\title{
Micro/nano-plastics occurrence, identification, risk analysis and mitigation: challenges and perspectives
}

\author{
Boda Ravi Kiran · Harishankar Kopperi • S. Venkata Mohan $\mathbb{1}$
}

Received: 23 July 2021 / Accepted: 29 December 2021 / Published online: 27 January 2022

(C) The Author(s), under exclusive licence to Springer Nature B.V. 2022

\begin{abstract}
Micro/nanoplastics (MP/NPs) are emerging global pollutants that garnered enormous attention due to their potential threat to the ecosystem in virtue of their persistence and accumulation. Notably, United Nations Environment Programme (UNEP) yearbook in 2014 proposed MPs as one among ten emergent issues that the Earth is facing today. MP/NPs can be found in most regularly used products (primary microplastics) or formed by the fragmentation of bigger plastics (secondary microplastics) and are inextricably discharged into the environment by terrestrial and land-based sources, particularly runoff. They are non-degradable, biologically incompatible, and their presence in the air, soil, water, and food can induce ecotoxicological issues and also a menace to the environment. Due to micro size and diverse chemical nature, MP/NPs easily infiltrate wastewater treatment processes. This communication reviews the current understanding of MP/NPs occurrence, mobility, aggregation behavior, and degradation/assimilation in terrestrial, aquatic (fresh \& marine),
\end{abstract}

B. R. Kiran · H. Kopperi · S. Venkata Mohan ( $\varangle)$ Bioengineering and Environmental Sciences Lab, Department of Energy and Environmental Engineering (DEEE), CSIR-Indian Institute of Chemical Technology (CSIR-IICT), Hyderabad 500007, India

e-mail: svmohan@iict.res.in; vmohan_s@yahoo.com

H. Kopperi · S. Venkata Mohan

Academy of Scientific and Innovative Research (AcSIR), Ghaziabad 201002, India atmospheric depositions, wetlands and trophic food chain. This communication provide current perspectives and understanding on MP/NPs concerning (1) Source, occurrence, distribution, and properties (2) Impact on the ecosystem and its services, (3) Techniques in detection and identification and (4) Strategies to manage and mitigation.

Keywords Plastic pollution - Microfiber plastics . Ecological risk - Wastewater treatment - Circular economy

$\begin{array}{ll}\text { Abbreviations } \\ \mathrm{AS} & \text { Acrylonitrile styrene copolymer } \\ \mathrm{Cd} & \text { Cadmium } \\ \mathrm{Co} & \text { Cobalt } \\ \mathrm{Cr} & \text { Chromium } \\ \mathrm{FeSO}_{4} & \text { Iron (II) sulfate } \\ \mathrm{H}_{2} \mathrm{O}_{2} & \text { Hydrogen peroxide } \\ \mathrm{HBrCDs} & \text { Hexabromocyclododecanes } \\ \mathrm{HDPE} & \text { High density polyethylene } \\ \mathrm{HNO} & \text { Nitric acid } \\ \mathrm{KI} & \text { Potassium iodide } \\ \mathrm{KOH} & \text { Potassium hydroxide } \\ \mathrm{LDPE} & \text { Low density polyethylene } \\ \mathrm{LC}-\mathrm{MS} & \text { Liquid chromatography-mass } \\ & \text { spectrometry } \\ \mathrm{NaCl} & \text { Sodium chloride } \\ \mathrm{NaI} & \text { Sodium iodide } \\ \mathrm{PA} & \text { Polyamide }\end{array}$




$\begin{array}{ll}\text { PAH } & \text { Polycyclic aromatic hydrocarbon } \\ \text { PBB } & \text { Polybrominated diphenyl } \\ \text { PBDEs } & \text { Polybrominated diphenyl ethers } \\ \mathrm{Pb} & \text { Lead } \\ \mathrm{PC} & \text { Polycarbonate } \\ \mathrm{PCB} & \text { Polychlorinated biphenyl } \\ \mathrm{PE} & \text { Polyethylene } \\ \mathrm{PE}-\mathrm{PP} & \text { Polyethylene and polypropylene } \\ & \text { copolymer } \\ \text { PEST } & \text { Polyester } \\ \mathrm{PET} & \text { Polyethylene terephthalate } \\ \mathrm{PMMA} & \text { Polymethyl methacrylate } \\ \mathrm{PP} & \text { Polypropylene } \\ \mathrm{PS} & \text { Polystyrene } \\ \mathrm{PU} & \text { Polyurethane } \\ \mathrm{Py}-\mathrm{GC} / & \text { Pyrolysis-gas chromatography/mass } \\ \mathrm{MS} & \text { spectrometry } \\ \mathrm{PVC} & \text { Polyvinyl chloride } \\ \mathrm{Ti} & \text { Titanium } \\ \mathrm{TiO}{ }_{2} & \text { Titanium oxide } \\ \mathrm{WWTP} & \text { Wastewater treatment plant } \\ \mathrm{Zn} & \text { Zinc } \\ \mathrm{ZnCl} & \\ & \text { Zinc chloride }\end{array}$

\section{Introduction}

Plastics have diversified to infiltrate all human activity and utilities by replacing wood and metals due to their affordability and versatility. The world's first synthetic plastic was produced by Leo Baekeland in 1907. The manufacture of plastics and use was phenomenal between 1950 and 2015, with terrestrial emissions accounting for $80 \%$ of plastic waste globally (Geyer et al. 2017). Plastic pollution has become a ubiquitously distributed and severe transboundary threat to natural ecosystems (Thompson 2015). Packaging materials $(39.5 \%)$, building materials $(20.1 \%)$, fishing gears (10\%), automotive parts (8.6\%), electronic utilities (5.7\%), and agro-industry components (3.4\%) account for the majority of plastic depositions, with the remainder consisting of household, medical waste, and sports equipment (Horton et al. 2017; Plastics Europe 2017). Recent Covid-19 pandemic upsurged the consumption of single-use plastics, namely personal protective equipment (PPE) kits, facemasks, and gloves, contributing to an additional $3.5 \%$ of global solid waste fraction (Patricio Silva et al. 2021). An estimated 4.90 trillion tonnes of plastics are dumped into oceans alone (O’Neill and Lawler 2021).

Microplastics (MPs; $<5 \mathrm{~mm}$ in diameter) and nanoplastics (NPs; $<100 \mathrm{~nm}$ in length) are becoming major concerns (Mariano et al. 2021), which can be found in the majority of regularly used products (primary) or can be formed by the fragmentation of bigger plastic litter (secondary) (Kokalj et al. 2021). Primary MPs are mass-produced from manufacturing and domestic applications, which includes exfoliating facial scrubs, toothpaste, detergents, personal care products, abrasive cleaning agents, plastic powder for molding, and synthetic clothing (nylon/polyester) (Wang et al. 2020a; Birch et al. 2020; Sun et al. 2019). Paints, adhesives, electronics, etc., are responsible for NPs release (Kihara et al. 2020). Secondary MP/NPs are formed by fragmentation of macroplastics (200-1000 $\mu \mathrm{M}$ ) through shear forces (Auta et al. 2017) which account for 70-80\% of all plastic released into the environment, while primary MPs contribute only 15-30\% (Mariano et al. 2021). MP/NPs infiltrate terrestrial, freshwater, and marine ecosystems from the equator to the poles and surface water to deep-sea sediments (Wang et al. 2016).

In general, MP/NPs enter the water bodies through domestic waste, sewage treatment plants (STPs), industrial effluents, stormwater, estuaries, and riverine transport, surface runoff, wind currents, and disposal practices (Liu et al. 2021; Sutton et al. 2016). MP/NPs are present as fragments, pellets, fibres, films, granules, and Styrofoam that vary with surface-mass area ratios (Koelmans et al. 2019). The chemical variation found in STPs includes polyethylene, polystyrene, and polypropylene which tend to float while polyethylene terephthalate (PET) and polyvinylchloride (PVC) are more likely to sink due to their density (Wu et al. 2017; Avio et al. 2017; Carr et al. 2016). The presence of MP/NPs in the air, water, and food can cause ecotoxicological issues (Zhang et al. 2020). Influx of MP/NPs causes growth reduction, fecundity, reduced immunity, and malformation in animals and human reproductive systems (Wong et al. 2020; Guzzetti et al. 2018). MP/NPs also act as vectors to adsorb tenacious organic pollutants, trace metals, and harmful additives that are multiple times higher than natural sediments (Jiang et al. 2020). Presence of MP/NPs in WWTPs, impact microbial communities, inhibit sludge hydrolysis and accumulate acids (Zhang and Chen 2020). 


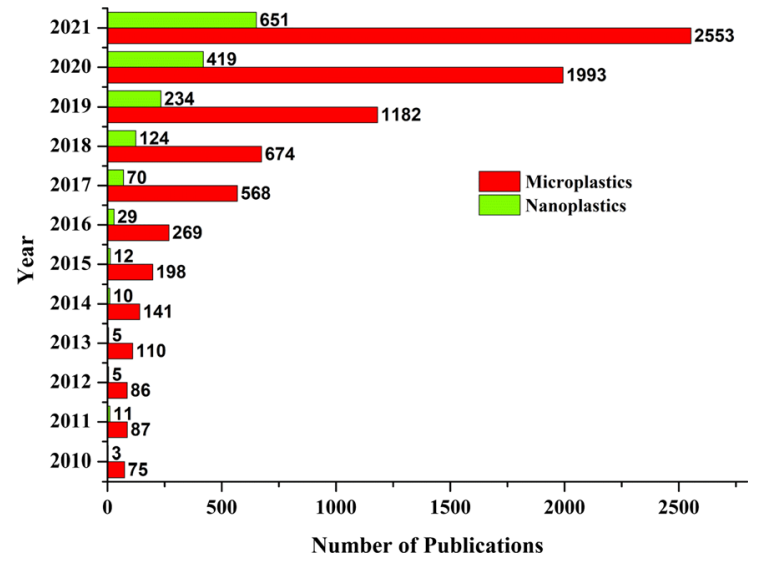

Fig. 1 The cumulative total of annual research papers published on microplastics and nanoplastics. Keyword used $=$ Microplastics and nanoplastics. Data source: www. sciencedirect.com

Plastic occurance, accumulation and persistence as MP/NPs in terrestrial and marine environments is becoming a major global concern. The issue of plastics was recognized by the United Nations (UN) Sustainable Development Goals (SDGs), specifically Goal 14-'Conserve and sustainably use the oceans, seas, and marine resources for sustainable development (Walker 2021). Using the keywords "microplastics" and "nanoplastics" as database search in indexed journals (ISI Science Direct), the publication number (MPs-7136/NPs -1369) is soaring exponentially, which elucidates growing interest in the scientific community (Fig. 1). This review aims to provide current perspectives on MP/NPs concerning (1) Source, occurrence, distribution, and properties (2) Impact on the ecosystem and its services, (3) Techniques in detection and identification of MP/NPs and (4) Remediation and management strategies to mitigate MP/NPs. The current understanding in the literature is highlighted, and future perspectives are indicated.

\section{Occurrence and distribution of Micro/nanoplastics}

\subsection{Terrestrial system}

The terrestrial domain is more susceptible to MP/NPs and the annual inputs from land exceeds the total MP/NPs floating in the global ocean (Yee et al.
2021; Wang et al. 2021; Hu et al. 2019). Soil bound MP/NPs originate from multiple sources, which includes sewage sludge/biosolids, domestic waste, irrigation, land fillings, fertilization, plastic film mulch, greenhouse materials, atmospheric deposition, tire abrasion and garden organic waste (Koutnik et al. 2021; Guo et al. 2020; Wang et al. 2020b). MP/NPs penetrate vertically via water infiltration, facilitated by tilling and action of soil microorganisms (O'Connor et al. 2019). The major source of MP/NPs in the soil is from WWTPs as $95 \%$ of MPs are retained in biosolids, and treated biosolids, in addition, are used as fertilizer in agriculture (van den Berg et al. 2020; Horton et al. 2017). Furthermore, a single-use facial scrub could release up to $10^{6}$ primary NPs into the domestic sewage system (Shen et al. 2019). Around 306.9 tonnes of microbeads are discharged into the environment, of which $80 \%$ are derived from STPs annually (Cheung and Fok 2017). Biosolids alone introduce approximately 44,000 to 430,000 tonnes of MP/NPs into North American and European grasslands each year (Nizzetto et al. 2016). Textiles contribute $35 \%$ of the MP/NPs, specifically in the oceans, in the form of synthetic microfibers (Xu et al. 2020). A single garment produces about 1900 microfibres, and around 700,000 microfibres can be released from a single load of laundry, according to the International Union for Conservation of Nature (IUCN) (Boucher and Friot 2017).

Plastics have a lower density than soil minerals, and once they enter the soil, it forms soil aggregates and alter soil physicochemical properties. It effects waterbinding capacity, soil density, porosity, soil integrity, soil surface cracking, and organic matter and influences the nutrient cycling process in the soil ecosystem (de Souza et al. 2019; Liu et al. 2017). Polyethylene, polystyrene, and polyvinylchloride nanoplastics (20 nm to $150 \mathrm{~nm}$ ) indirectly influence soil productivity and directly alter the soil microorganisms and fauna communities (Wahl et al. 2021). Organic fertilizers and compost act as vectors for MP/ NPs into the soil (Bläsing and Amelung 2018). Plastic mulch films are used extensively as soil conditioners in agriculture (Gao et al. 2019). Farmlands in China used $\sim 1.47$ million tonnes of plastic mulch with film content reaching $502 \mathrm{~kg} \mathrm{ha}^{-1}$ soil in all provinces and regions (Zhang et al. 2016). Farmlands reported 62.5 particles $\mathrm{kg}^{-1}$ in deep soil, 78.0 particles $\mathrm{kg}^{-1}$ in shallow soil, and $1.9 \pm 0.87$ particles $\mathrm{kg}^{-1}$ in garden 
soils (Liu et al. 2018). A study on the rice-fish coculture ecosystem showed MPs concentration in soil ranges between 10 to 78 particles $\mathrm{kg}^{-1}$ (Lv et al. 2019; Liu et al. 2018). MPs congregations in Sydney's industrial zones ranged from 300 to $67,500 \mathrm{mg} \mathrm{kg}^{-1}$ (Fuller and Gautam 2016). The dispersal of plastic debris in coastal belts, vegetable farmlands, and riparian forest zones found MPs concentration ranged from 7100 to 42,960 particles $\mathrm{kg}^{-1}$ (Zhang and Liu 2018). Due to its large mass-surface ratio and hydrophobic nature when combines with other persistent organic pollutants (POPs), heavy metals, and antibiotics, they serve as vectors for toxic chemicals (Wang et al. 2020b; Hodson et al. 2017). MPs-POP mixtures threaten the terrestrial environment by adsorbing various POPs (Yang et al. 2019a, b). Microplastics absorb pesticides and hinder the chemical degradation of polyethylene film residues, resulting in pesticides accumulation (Ramos et al. 2015). MPs affinity to adsorb antibiotics was also reported ( $\mathrm{Li}$ et al. 2018).

Soil act as a preliminary sink and most MP/NPs are deposited in landfills. Between 1950 and 2015, global trash production was expected to total 6300 million tonnes, with landfills and other environmental compartments accounting for $79 \%$ of the total (Patricio Silva et al. 2021; Ng et al. 2018). A study in Finland enumerated MP/NPs particles up to 4.5 items $\mathrm{L}^{-1}$ with size $>1 \mathrm{~mm}$ in diameter (Kilponen 2016). Plastic trash blowing from landfills, if not adequately buried, can affect the soil and reach aquatic habitats (Peng et al. 2017). The particle and mass concentrations of MP/ NPs in the untreated leachate were $235.4 \pm 17.1 \mathrm{item} /$ $\mathrm{L}$ and $11.4 \pm 0.8 \mathrm{~g} / \mathrm{L}$, respectively, with particles size less than $50 \mu \mathrm{m}$ (Sun et al. 2021). Fresh Kills landfills leached most of the medical waste on New York beaches in 1987-1988 (Hale et al. 2020). Natural catastrophes (hurricanes, tsunamis, and wildfires), construction and demolition landfills frequently aid in the deposition of plastic debris (Brand et al. 2018). $\mathrm{PE}$ and PP were the predominant polymer types in municipal solid waste (MSW) landfills with sizes ranging from 100 to $1000 \mu \mathrm{m}$ (He et al. 2018).

\subsection{Air}

Micro/nanoplastics are released into the air due to wastewater treatment plant operation and (Chang et al. 2020) mechanical activities such as severe wind events, sea surface spray and wave breaking which often entrain them into the atmosphere (Brahney et al. 2021). Sea-spray releases MP/NPs from the maritime environment into the atmosphere, resulting in a global extrapolated value of 136,000 tonnes blowing on shore per year (Allen et al. 2020). Fibre, film, foam, and fragment morphologies have been dominant in atmospheric deposition and air masses (Zhang et al. 2020). MPs have a higher density than air (1.225 g/ $\mathrm{L}$ at $15{ }^{\circ} \mathrm{C}$ at sea level), and their density diminishes as altitude rises (Revel et al. 2018). The commonly distributed MP/NPs in environment are 0.91-0.93 $\mathrm{g} / \mathrm{cm}^{3}$ of low-density polyethylene, $0.94 \mathrm{~g} / \mathrm{cm}^{3}$ of high-density polyethylene, $0.85-0.83 \mathrm{~g} / \mathrm{cm}^{3}$ of polystyrene, $1.02-1.05 \mathrm{~g} / \mathrm{cm}^{3}$ of polyamide, $1.37 \mathrm{~g} / \mathrm{cm}^{3}$ of polyester, $1.38 \mathrm{~g} / \mathrm{cm}^{3}$ of PVC, $1.2 \mathrm{~g} / \mathrm{cm}^{3}$ of polycarbonate and $1.42 \mathrm{~g} / \mathrm{cm}^{3}$ of polyformaldehyde (Rezaei et al. 2019). MP/NPs suspended in atmospheric air correspond to synthetic fibres and, upon inhalation, cause respiratory disorders (Wright et al. 2020). A significant amount of MPs are ejected from tyres (100,000 metric tonnes) and brakes (40,000 tonnes) each year which get transported through the air (Evangeliou et al. 2020). Car tyres and brake systems are responsible for 5-10\% of worldwide ocean plastic pollution and 3-7\% of PM2.5 in the air (Evangeliou et al. 2020). According to a study, each person in the United States generates $4.7 \mathrm{~kg}$ of tire wear microplastics per year ${ }^{-1}$, equating to 1.8 million metric tonnes per year $^{-1}$ (Hale et al. 2020). Road dust has been recognized as an important source of MP/NPs in urban/sub-urban areas. The atmospheric deposition of MP/NPs is higher in indoor environments, and about $33 \%$ of microfibres contain petrochemicals (Wu et al. 2019). On normal exposure, $>900 \mathrm{MP} / \mathrm{NPs}$ particles are ingested by a child per year (Abbasi et al. 2019).

\subsection{Aquatic system}

In the early 1970s, the first report on MPs occurance in marine system was published (Carpenter and Smith 1972). MPs enter into fresh and marine environments mainly through natural erosion and human activities (industrial and domestic wastewaters, aquaculture, and tourism) (Guo et al. 2020; Birch et al. 2020). "River to the ocean" is one of the major pathways for plastic reservoirs (Wu et al. 2019). Eight rivers in Asia (Yangtze, Yellow, Indus, Hai He, Ganges, Mekong, Amur, and Pearl), and two rivers in Africa (the Nile 
and the Niger) are the sources of $90 \%$ of the plastics that reach the sea every year (Sadeghi et al. 2021). Every year river-fed estuaries dump 1.15 to 2.41 million tonnes of plastic trash into the sea (Lebreton et al. 2018). The North-western Pacific Ocean and Arabian Bay are widely polluted by MP/NPs with concentrations ranging from 640 to 42,000 items $\mathrm{km}^{-2}$ and $4.38 \times 10^{4}$ items per $\mathrm{km}^{-2}$ (Xu et al. 2019). An estimated 15-51 trillion MP/NPs particles (93-236 thousand metric tons) were found in oceans (Naik et al. 2019). Plastic pollution, dumping, and trash eventually goes downstream into estuaries and coastal seas. Changing rainfall, wind speed, waves, and oceanic currents contribute to the transfer of pollutants into seawater (Cózar et al. 2014). Agricultural runoff, soil erosion, and atmospheric deposits also transfer MP/NPs in marine ecosystems (Hale et al. 2020). Field studies conducted on the banks of Ciwalengke River, Indonesia, showed the presence of MP/NPs as primary fibres with concentrations ranging from 5.85 particles per litre in surface water and 3.03 particles per $100 \mathrm{~g}$ of sediment in sizes ranging from 50 to $2000 \mu \mathrm{m}$ (Alam et al. 2019). The abundance of MPs ranged from 112 to 234 particles $\mathrm{kg}^{-1}$ dry weight in lake Bolsena shoreline sediments of central Italy (Lake Chiusi) (Fischer et al. 2016). Microalgae also can colonize MP/NPs and increase their specific density through biofouling and hetero-aggregation (Mateos-Cárdenas et al. 2021). In 2011, Japan's Tsunami injected 5 million tonnes of plastic debris into the Pacific, which is approximately the amount of plastic waste entering the ocean each year (Murray et al. 2018).

\subsection{Wastewater systems}

Anaerobic digestion is a prevalent approach for handling sewage sludge (in WWTPs), wherein particulate organic waste gets converted to soluble substrates is the first step. Polyethylene, polyamide, polyvinyl chloride, and polystyrene in activated sludge impede anaerobic digestion and have varying effects depending on their physicochemical nature (Zhang and Chen 2020). Additives or toxic chemicals released from MP/NPs rupture microbial cells or inhibit key enzymes related to acidogenesis (hydrolysis and fermentation) and methanogenesis and hinder anaerobic digestion (Azizi et al. 2021). MP/NPs also penetrate the exopolysaccharide matrix, alter protein secondary structures, and damage phospholipids (Azizi et al. 2021). Following MP/NPs exposure, changes in the activity of key enzymes such as protease, cellulase, glucosidase, acetate kinase, butyrate kinase, coenzyme $\mathrm{F} 420$, etc. were observed to cause changes in the digester performance (Azizi et al. 2021). The effects of various doses of polyvinyl chloride and polystyrene (10-200 particles $\mathrm{g}^{-1}$ ) on waste-activated sludge's anaerobic digestion negatively affected hydrolysis rate and biogas generation (Li et al. 2020). After exposing digesters to polystyrene nanoparticles, marked variations in $\mathrm{pH}$, volatile fatty acids, and ammonia nitrogen profiles were reported (Zhang et al. 2020). Microbial communities also resulted in a considerable decrease in the digester upon short and long-term exposure to MP/NPs (Azizi et al. 2021).

\section{Micro/nanoplastics degradation}

Plastics can disseminate micro-and nanoplastics either via biodegradation or non-biodegradation processes (Yee et al. 2021). Plastics are long-chain organic compounds, and their degradation is determined by the change in physical properties (shape, size, porosity, surface area, and crystallinity) and their ability to interact with other pollutants (Cai et al. 2017; Campanale et al. 2020). Once disposed of, plastic waste undergoes chemical, biological, and environmental changes, breaking large pieces of plastics into micro and nanoplastics (Allen et al. 2020). Thermal degradation, physical deterioration, photodegradation, thermo-oxidative degradation, biodegradation, sand friction, and hydrolysis are some of the weathering mechanisms that degrade larger plastic polymers to MPs (Hale et al. 2020; Wu et al. 2019) (Fig. 2). NPs are formed when MPs are exposed to light (visible and UV rays) at moderate temperatures $\left(30{ }^{\circ} \mathrm{C}\right.$ ) (Jiang et al. 2020). Hydrolysis and photodegradation are natural chemical reactions that use water molecules and UV-visible light to break down chemical bonds in polymers and turn them into monomeric forms (Yee et al. 2021). The fragmentation of polystyrene down to the nanoscale occurred in four weeks inside a weathering chamber (Kihara et al. 2020). Throughout the backbone of plastic polymers, heteroatoms $(\mathrm{O}, \mathrm{N}$, and S) serve as sites for hydrolytic/enzymatic processes and facilitate breakdown into low molecular weight 


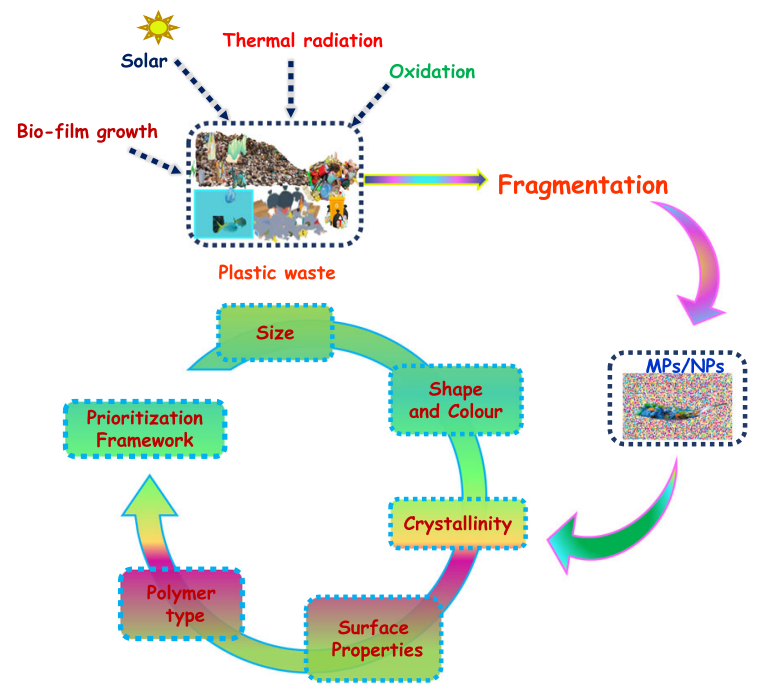

Fig. 2 Micro and nanoplastics fragmentation in terrestrial and aquatic systems and associated physcio-chemical properties

fragments that microbial cells can assimilate $(\mathrm{Ng}$ et al. 2018). The chemical structure of polymers changes at the molecular level, such as chain scission, crosslinking, and the inclusion of oxygen-containing functional groups (esters, ketones, and alcohols) into the surface of plastic particles lowering their hydrophobicity (Yee et al. 2021). Non-biodegradation methods break down polymeric structures, changing mechanical characteristics and increasing surface zone, ensuing increased physico-chemical reactions and interfaces with microbes (Lucas et al. 2008). Microorganisms such as bacteria, fungi, and other eukaryotic colonizers secrete extracellular enzymes and mediate biodegradation (Naik et al. 2019; Enfrin et al. 2019). Biofilm formation also promotes the formation of hetero-aggregates where MP/NPs become sticky because of extracellular polymeric substance matrix (Wu et al. 2019). High saline content in marine environments, combined with naturally present microbes, promotes plastic disintegration faster than in terrestrial ecosystems ( $\mathrm{Ng}$ et al. 2018). The structural integrity of the plastics is further weakened by subsequent interactions with wind, waves, solar UV radiation, temperature, additives, environmental conditions, and other abrasive interactions released through delamination (Jiang et al. 2020).

\section{Properties of micro/nanoplastics}

Microplastics' physical properties are generally associated with particle size, shape, and color, whereas chemical properties associate with crystallinity, surface properties, toxic metals, and additives adhered on MP/NPs surfaces (Hildebrandt et al. Lambert et al. 2017).

\subsection{Size}

Micro/nanoplastics sizes are often determined by the sampling and analysis methods. MPs come in various sizes, but the most common are $1 \mu \mathrm{m}$ to $5 \mathrm{~mm}$, whereas NPs are $<100 \mathrm{~nm}$ in length (Murray and Örmeci 2020; Hartmann et al. 2019). The National Oceanic and Atmospheric Administration proposed these dimensions. The Joint Group of Experts later adopted the Scientific Aspects of Marine Environmental Protection (GESAMP 2016) and the United Nations Environmental Program (UNEP 2014). Currently, the two most common MP/NPs classification methods are sieve retention and microscopic imaging. The dimensions $25 \mathrm{~mm}, 100 \mathrm{~mm}$, and $500 \mathrm{~mm}$ were the most frequently identified sizes in WWTP influent and effluents (Mintenig et al. 2017). Samples from the Atlantic Ocean revealed MPs in size 20 to $40 \mu \mathrm{m}$, accounting for $64 \%$ of the total detected particles (Simon et al. 2018; Enders et al. 2015), where atmospheric depositions accounted for microfibers of $\sim 5000 \mu \mathrm{m}$ in size (Cai et al. 2017). The size and ubiquitous distribution of MP/NPs in the aquatic and marine environment facilitate their availability to pelagic and benthic habitats (Campanale et al. 2020). Several species of zooplankton (Calanusfinmarchius, Euphausia pacifica, and Neocalanus cristatus), bivalves, macro-sized invertebrates, and fish ingest a wide range of MP/NPs ranging from $0.5 \mathrm{~nm}$ to $816 \mu \mathrm{M}$ (Botterell et al. 2019; Lehtiniemi et al. 2018).

\subsection{Shape}

The shape is one of the important indicators used for microplastics classification. MP/NPs come in a wide range of shapes (fragment, foam, paint, pellet, foil, sphere, fibre, film, line, bead, flake, sheet, granule, and nurdle) (Campanale et al. 2020; Zhang et al. 2020; Koelmans et al. 2019). The primary form of microplastics, degradation, erosion process and the 
duration time in the environment all influence the shape of MP/NPs (Murray and Örmeci 2020). Fibres and fragments are the dominant shapes and account for $52.7 \%$ of wastewater and urban atmospheric depositions (Annenkov et al. 2021). Fibre particles form due to mechanical abrasion and chemical weathering, whereas fragmented microplastics may form due to greater plastic items exposed to fatigue or UV light (Zhou et al. 2020). The shape of MP/NPs influences pollutant transport in the environment. Films are thin and have a bigger surface area than fragments of the same mass for atmospheric conveyance (Allen et al. 2020). Microfibres and fragments are dominant shapes found in international waters (Wang et al. 2020a).

\subsection{Colour}

Colour is one of the most important parameters for identifying plastic debris and potential contaminations in sample preparation. Various MP/NPs have been documented including red, orange, yellow, brown, tan, off-white, white, grey, blue, and green (Murray and Örmeci 2020; Rochman et al. 2019). Particles with dark, transparent, white, or translucent may be underrepresented (Hartmann et al. 2019). Blue and red fibres are the most commonly reported colours (Bergmann et al. 2019). Polypropylene has been clear and transparent, while polyethylene and polyethylene with low-density have been assigned opaque colors (LDPE) (Zhang et al. 2020). Microplastic discoloration can occur during weathering and sample preparation $\left(\mathrm{H}_{2} \mathrm{O}_{2}\right.$ - oxidative digestion), which should be considered when reporting and interpreting data (Allen et al. 2020). Marine organisms commonly ingest bright color NPs particles similar to natural foods. Zooplankton, euphausiid, copepods, and fish larvae ingest MPs predominantly in blue, red, green, and black (Botterell et al. 2019).

\subsection{Chemical additives}

MPs and NPs are mostly additives and basic polymeric materials generated from plastics and chemicals absorbed from the environment (Table 1). Plastic toxicity is associated with built-in chemicals (i.e., monomers, solvents, catalysts, additives-dyes, plasticizers) (McGivney et al. 2020). Low molecular weight additives entrenched into the polymer matrix are weak and leaches readily into surrounding water bodies (flame retardants from electronic items; PET oligomers from bottles and food trays; $\mathrm{Pb}$ from unplasticized PVC pipes; nonylphenol from food contact materials and Sb from PET water bottles) (Schwinghammer et al. 2020; Dobslaw et al. 2020). During plastic production, additives are added for desired colour, transparency and to improve the working liability of the product, which makes the polymer more resistant to degradation from physical (temperature, ozone, and light radiation), mechanical, electrical, and biological (fungi, bacteria) agents (Hale et al. 2020). Inert or reinforcing fillers, dyes, UV stabilizers, plasticizers, lubricants, and flame retardants are additives. In addition, wood, graphite, glass fibres, rock flour, kaolin, cotton flakes, jute, clay or linen, cellulose pulp are also used as additives (Campanale et al. 2020; Dobslaw et al. 2020). These additives upgrade the plastic properties, but most are toxic and potential soil, water, and air contaminants. Ingestion or inhalation of these chemicals disrupts the endocrine system and causes hormonal imbalance, asthma, reproductive problems, metabolic disorders, and neuro-developmental conditions (Schwinghammer et al. 2020). Bisphenol A, phthalates, heavy metals, and brominated flame retardants are most common additives $(\mathrm{Li}$ et al. 2021).

\subsection{Crystallinity}

Crystallinity is ordered structural linkages that influence the plastics' density, permeability, and swelling behavior (Botterell et al. 2019; Lambert et al. 2017). The crystallinity of MP/NPs changes with residence time in the environment. The breakdown of the amorphous region in the polymer promotes overall crystallinity and reduces the size of MP/NPs (Campanale et al. 2020). The materialization of crystallites might differ in toxicity and will alter MP/NPs from their counterparts. It eventually influences particle shape, size, surface area, and chemical properties like adsorption of pollutants, additives and consecutively affects ingestion rate (Botterell et al. 2019; Gao et al. 2019).

\subsection{Surface properties}

The surface property primarily involves surface area and surface chemistry. With the decrease in particle size, MP/NPs surface area increases, and particles at 
Table 1 Various Chemical additives, polymers and metals with plastics and their effect on the human health

\begin{tabular}{|c|c|c|c|}
\hline Additives & & Effect on human health & References \\
\hline Plasticizers & $\begin{array}{l}\text { 1,2-benzenedicarboxylic acid } \\
\text { Chlorinated paraffins, Dicyclohexyl phthalate (DCHP) } \\
\text { di-C7-11-branched and linear alkyl esters (DHNUP) } \\
\text { Butyl benzyl phthalate (BBP) } \\
\text { Diethyl phthalate (DEP) } \\
\text { Diheptyladipate (DHA) } \\
\text { Formaldehyde, 4,4'-methylenedianiline (MDA) } \\
\text { Dipentyl phthalate (DPP) } \\
\text { Diisobutyl phthalate (DiBP) } \\
\text { Diisoheptylphthalate (DIHP) } \\
\text { Heavy metals-Zinc, Cadmium, Tin, Lead, Titanium, } \\
\text { Barium }\end{array}$ & $\begin{array}{l}\text { Neuronal toxicity } \\
\text { Breast cancer } \\
\text { Cardiovascular } \\
\text { Kidney diseases } \\
\text { Metabolic and mental } \\
\text { disorders } \\
\text { Neuro-degenerative disorder }\end{array}$ & $\begin{array}{l}\text { Campanale } \\
\text { et al. } \\
(2020) \\
\text { Engwa et al. } \\
\quad(2019) \\
\text { Verla et al. } \\
\text { (2019) } \\
\text { Jeong and } \\
\text { Choi } \\
\text { (2020) }\end{array}$ \\
\hline Biocides & $\begin{array}{l}\text { Arsenic trioxide } \\
\text { Triclosan } \\
\text { Triphenyltin hydroxide } \\
\text { Butyltin trichloride } \\
\text { Dimethyltin dichloride } \\
\text { Dibutyltin dichloride } \\
\text { Tetrabutyltin } \\
\text { Tributyltin chloride } \\
\text { Heavy metals- Antimony, Copper, Mercury, Arsenic, Tin }\end{array}$ & $\begin{array}{l}\text { Metal-estrogen } \\
\text { Mutagen } \\
\text { Carcinogen } \\
\text { Brain damage } \\
\text { Congenital disabilities } \\
\text { Lung, skin, liver, bladder, } \\
\text { kidneys, } \\
\text { Gastrointestinal damage }\end{array}$ & \\
\hline Flame retardants & 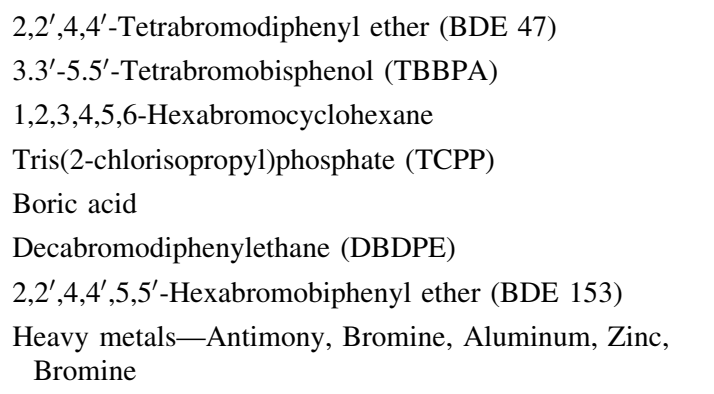 & $\begin{array}{l}\text { Carcinogen } \\
\text { Apoptosis } \\
\text { Genotoxicity } \\
\text { Osteomalacia and } \\
\text { bone fractures } \\
\text { DNA methylation }\end{array}$ & \\
\hline $\begin{array}{l}\text { Stabilizers, Antioxidants } \\
\text { and Organic pigments }\end{array}$ & $\begin{array}{l}\text { Bisphenol A } \\
\text { Fatty acid amides } \\
\text { 2-tert-Butyl-4-methoxyphenol } \\
\text { Triglycidylisocyanurate (TGIC) } \\
\text { 2-t-butyl-4 hydroxyanisole (BHA) } \\
\text { Tris(2,4-di-tert-butylphenyl) phosphate } \\
\text { Butylated hydroxytoluene (BHT) } \\
\text { Tris-nonyl-phenyl phosphate (TNPP) } \\
\text { 4-Nonylphenol } \\
\text { Irganox } 1010 \\
\text { 4-Octylphenol } \\
\text { Heavy metals-Aluminum, Manganese, Barium, Cobolt, } \\
\text { chromium, Lead, Titanium, Tin, Cadmium, Aluminum }\end{array}$ & $\begin{array}{l}\text { Metabolism changes } \\
\text { DNA methylation } \\
\text { Anemia } \\
\text { Neurological disorder } \\
\text { Cardiovascular } \\
\text { andendocrine deficits } \\
\text { Hypertension } \\
\text { Miscarriages } \\
\text { Disruption of nervous } \\
\text { Brain damage } \\
\text { Infertility }\end{array}$ & \\
\hline
\end{tabular}


the nanoscale have a marked impact (Gao et al. 2019). Although the surface area is not widely recognized, microbeads can be calculated using the spherical equivalent diameter (Botterell et al. 2019). Nanoscale particulates are assumed using geometrical estimates, resulting in a sevenfold interpolation of the surface area (Campanale et al. 2020). The plastic surface is affected by photo- and oxidative degradation processes that generate new functional groups when reacted with $\mathrm{OH}$ radicals, $\mathrm{O}$ and $\mathrm{N}$ oxides, and other photo-generated radicals (Schwinghammer et al. 2020). These pathways disrupt the plastic surface area, and microscopic particles are released upon ingestion, chemical leaching, and formation of angular-shaped NPs from primary microbeads (Lambert et al. 2017). Furthermore, surface chemistry significantly impacts particle-biota interactions as the microbial community utilizes the oxygenated binding sites (McGivney et al. 2020; Campanale et al. 2020).

\section{Impact on the environment}

\subsection{Soil}

Micro/nanoplastics are a serious threat to soil biota because they inhibit plant growth, organism reproduction, and soil biodiversity (Hale et al. 2020). Soil serves as a habitat for terrestrial animals, and the ecotoxicological effects of MP/NPs on soil fauna are exuberantly increasing (Fig. 3). MP/NPs are ingested by soil invertebrates and poultry, providing a potential gateway to enter humans and animals due to their small size (Cox et al. 2019). Species like nematodes, snails, mice, isopod, collembolan, and chicken are studied with different MP/NPs (HDPE, PVC, PE, PS, PA, and PET), of which earthworm studies are predominant ( $\mathrm{Ng}$ et al. 2018). The toxicity of MP/ NPs on soil biota includes growth suppression, energy metabolism disturbance, immunological responses, locomotion reduction, gastrointestinal disorders, gut microbiota dysbiosis, metabolic abnormality, and mortality (Wang et al. 2020b). In vertebrates, leaching from MP/NPs additives such as bisphenol A and phthalates disrupt the endocrine system through the estrogenic effect (Zhang et al. 2020). Polystyrene MPs showed damage to cholinergic, GABAergic neurons, and oxidative stress kinase (Lei et al. 2018). Lumbricus terrestris (earthworm), when exposed to $28 \%$ PE-
MP in dry plant litter, experienced growth reduction and eventually cell death (Huerta Lwanga et al. 2016). A cross-section study reported the existence of MPs debris in the gastrointestinal tract and gut system of domestic live-stock and terrestrial birds (Omidi et al. 2012). Sunlight, oxygen availability, high temperature, soil microbes, and terrestrial biota in the top soil layer function as plastic garbage degradative habitat (Wang et al. 2020a). Antibiotic resistance genes are transported, deposited, and dissipated in soil by MP/ NPs (Sun et al. 2019). Microbial enzymes (dehydrogenase and fluorescein diacetate hydrolysis) tend to increase plastic mulch residues (Wang et al. 2016). MP/NPs can affect gene expression and alter the microbial cellular structure. They penetrate cells through endocytosis (Zhang and Chen 2020). MP/ NPs with exopolysaccharides (EPS) in wastewater systems are mediated by functional groups such as carbonyl, amide groups, and side chains of lipids or aminoacids (Feng et al. 2018). PS-NPs showed a change in the secondary structure of proteins in EPS (Catarino et al. 2021).

\subsubsection{Plant and macrophytes}

Plants metabolize a wide range of pollutants (MPs, NPs, and POPs) either by avoiding its uptake or detoxifying by various enzymatic activities in the plant cell (Dobslaw et al. 2020; Ng et al. 2018) (Fig. 3). In the plant root zone, soil microorganisms and animals participate in MP/NPs degradation and protection from toxic effects (de Souza et al. 2019). MP/NPs alter soil fertility and significantly affect growth, biomass, root traits, nutrient uptake, and soil microbial activities (Bianco and Passananti 2020; Zhang et al. 2020). MP/NPs adsorption and internalization have been observed in plants used for human consumption (Triticum aestivum, Allium cepa, Allium fistulosum, Lactuca sativa, and Zea mays) and macrophytes (Lemna minor and Fucus vesiculosus) (Mateos-Cárdenas et al. 2021). Polystyrene (PS), polyethylene (PE), polypropylene (PP), cotton, and rayon fibres were commonly found adhering to plant surfaces (Mateos-Cárdenas et al. 2021). Triticum aestivum and Lactuca sativa internalize $200 \mathrm{~nm}$ PS nanobeads and $2.0 \mu \mathrm{m}$ polymethylmethacrylate microbeads, respectively ( $\mathrm{Li}$ et al. 2020). PS nanobeads $(10 \mathrm{~nm}$ to $200 \mathrm{~nm})$ was internalized in the root maturation zone and translocated to leaf vessels via 


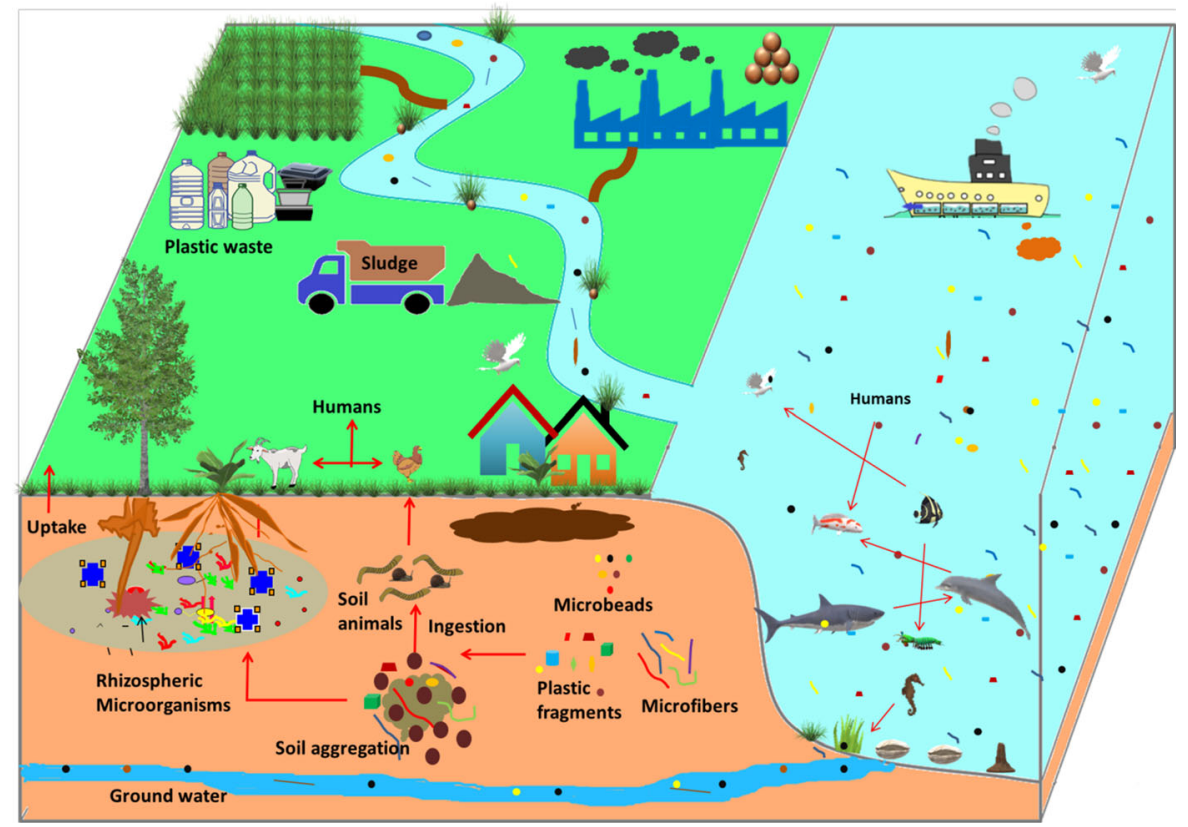

Fig. 3 Micro/nanoplastics distribution across different food trophic levels and their interaction with biological processes in terrestrial, fresh and marine systems

vascular tissues in Zea mays L. (Sun et al. 2021), $C$. pteridoides (Yuan et al. 2019), and Vigna radiata (Chae and An 2017). Apple, broccoli, and carrots showed significant quantities of MPs per gram (Conti et al. 2020). In a study, co-culturing Lolium perenne (ryegrass) with Aporrectodea rosea (rosy-tipped earthworm) with different MPs (PE, HDPE, and fibres) showed reduced plant biomass, $\mathrm{pH}$, and inhibited growth (Boots et al. 2019). Various plant species and soil types have different reactions. Plants and macrophytes act as potential vectors for trophic transfer of MP/NPs into natural food webs. Duckweed is toxic to amphipods (Mateos-Cárdenas et al. 2021), F. vesiculosus is toxic to Littorina littorea (Gutow et al. 2019), and $V$. radiate is toxic to Achatina fulica (Mateos-Cárdenas et al. 2021. High doses of MPs are used on a laboratory scale to identify and impact soil biota easily. However, MPs levels in human-impacted soil are unlikely to be greater than $0.1 \%$ dry weight (Sun et al. 2021).

\subsubsection{Mangroves}

Mangrove wetland is an intertidal ecosystem that acts as a barrier for retaining land-based pollutants, including MP/NPs (Helcoski et al. 2020; Li et al.
2020). Nor and Obbard (2014) first reported MPs in mangroves with concentrations ranging from 12 to 62.7 items per kg. Cienaga Grande de Santa Marta (CGSM), one of the coastal lagoons declared as RAMSAR wetland, consists of MP/NPs concentrations oscillated between 31 and 2863 particles per $\mathrm{kg}$ of dry sediment (Garcés-Ordóñez et al. 2019). The plastic debris is always accumulated on the leaf's surface, trunk, pneumatophores and transported by ocean currents and storm runoff from the land (Zhou et al. 2020). Fibres, foams, and films are dominant MP/ NPs detected in mangrove sediments worldwide (Duan et al. 2020). MP/NPs inhibit the growth of mangrove seedlings, loss of foliage, and negatively affect mollusks, crabs of the Uca genus, and crustacean habitats that live in soils associated with mangroves (do Sul et al. 2014). Four species of juvenile fish (viz. Ambassis dussumieri, Terapon jarbua, Mugil sp., and Oreochromis mossambicus) growing in KwaZulu-Natal mangroves unveiled fibres $(68 \%)$ and fragments $(21 \%)$ with $0.79 \pm 1$ particle per fish (Naidoo et al. 2020). Similar findings were found in each fish's gills, stomach, and intestine in the Zhanjiang mangrove wetlands, where $2.83 \pm 1.84$ items per individual MPs were reported (Huang et al. 2020). Gerreidae sps. (Eugerres brasilianus, 
Eucinostomus melanopterus, and Diapterus rhombeus) found in estuaries and mangroves ingested MPs and showed a reduction in gut weight and false satiation (Ramos et al. 2012).

\subsection{Aquatic biota}

Plastic pollution is an upsurging global concern in aquatic systems, spreading even to the most remote habitats (Fig. 3). Plastic debris ranging from microscopic to high density is prevailing in benthic and pelagic habitats of rivers, seas, and remote regions of Artic to Antarctica (Bianco and Passananti 2020). MP/ NPs have been identified as a major concern for biodiversity loss, climate change, and threatening living biota.

\subsubsection{Fresh water systems}

In recent years, freshwater systems such as ponds, lakes, estuaries, and rivers have attracted as much attention as oceans in terms of MP/NPs flux (Wong et al. 2020) through domestic waste, industrial effluents, and sewage disposal sites (Meng et al. 2020; Hu et al. 2019). Particle qualities (size, shape, and density) and physical forces (flow velocity, water depth, sediment topography, tidal cycles, and urban runoff), and anthropogenic activity (e.g., dam release) influence MP/NPs movement in freshwater systems (Helcoski et al. 2020; Ziajahromi et al. 2017). MP/NPs have been found in freshwater systems across the continents (Lahens et al. 2018). The Danube delivers 4.2 tonnes of plastic each day to the Black Sea (Lechner et al. 2014). Microbeads, raw plastic (pellets and flakes), films, fibres, and fragments are types of MP/NPs found across the freshwater streams, where microbeads and fibres are dominant (Li et al. 2021). Plastic debris accumulation in aquatic habitats alters light penetration and affects biogeochemical cycles in the water column (Chen et al. 2020). NPs absorbed on the surface of microalgae cause a shading effect and decrease the fluidity of cell membranes (Zhu et al. 2021). Internalized NPs reduce carbohydrate metabolism and decrease cellular esterase activity, electron transport rate, and lipid reserves, thus modulating algal energy metabolism (Zhu et al. 2021). Large plastic particles, such as fishing ropes and nets, entangle turtles, birds, and mammals, whereas small particles are ingested directly, causing a gut obstruction (Horton et al. 2017). MP/NPs in freshwater systems severely impact the ecosystem as they are the major reliable sources of food and drinking water for humans (Senathirajah et al. 2021). NPs last longer in the body than MPs and are transported to the digestive gland. Trophic transfer of NPs was investigated, and increased uptake causes tissue inflammation, reduced lipid stores, nutrient uptake, and membrane instability in digestive cells (O'Neill and Lawler 2021). Daphnia magna and Danio rerio (Zebra fish) are widely used biological and toxicological research models to assess MP/NPs in freshwater systems (Jiang et al. 2020). When exposed to 0.1, 1 , and $10 \mathrm{ppm}$ of polystyrene NPs, Zebrafish embryos, accumulation in embryonic tissues and choroid membranes was observed, thereby influencing the inter or trans generational toxicity (Pitt et al. 2018). Freshwater fauna (Daphnia magna, Gammarus pulex, and Lumbriculus variegutus) ingested MPs and translocated them from cells to oil storage droplets and faces (Imhof et al. 2013). A field study in French water streams showed 7 out of 11 gobies (Gobio gobio) contained MPs in their tissues (Sanchez et al. 2014). Polystyrene NPs of sizes $20 \mathrm{~nm}$ to $39.4 \mathrm{~nm}$ affect the biomass, photosynthetic efficiency, and mortality rate of Chlorella sp., Daphnia magna, Raphidocelis subcapitata, and Scenedesmus obliquus (Chae and An 2017). Organisms predate freshwater species at higher trophic levels, and MP/NPs consumed have cascade impacts on the ecosystem's health(Nizzetto et al. 2016; Li et al. 2015).

\subsubsection{Marine systems}

Marine litter is a huge environmental and economic issue around the world. Plastic garbage reaches the ocean at a pace of 4.8 to 12.7 million tonnes per year, with $80 \%$ of it coming from land-based sources worldwide (Mofijur et al. 2021; Raju et al. 2018). Rivers, lakes, sewage effluents, and anthropogenic activities are major gateways to transport plastic debris to oceans (Xu et al. 2019). The European Union's Marine Strategy Framework Directive (MSFD), the OSPAR commission, the Stockholm Convention, and International Pellet Watch have all focused on marine litter problems to protect and conserve its resources (Stockholm convention, UNEP 2018; OSPAR 2014). Aerial surveys in the Pacific Ocean discovered 79 thousand tonnes of plastic 
floating over a 1.6 million $\mathrm{km}^{2}$ area, dubbed the "Great Plastic Garbage Patch." (Lebreton et al. 2018). The density of sea water is $1.02-1.07 \mathrm{~g} / \mathrm{cm}^{3}$, while that of plastic is $0.8-1.5 \mathrm{~g} / \mathrm{cm}^{3}$, which tends MPs to float on water surfaces (Wang et al. 2020a). PS, PP, PE, PU, PVC, and PET are among the most common plastics contributing to marine pollution (Annenkov et al. 2021; Birch et al. 2020). Nine sediment samples at 2340-5570 m depth analyzed in the Arctic region showed widespread NPs (42-6595 MPs $\mathrm{kg}^{-1}$ ) (Bergmann et al. 2019). MPs will outnumber fish in oceans by 2050, according to World Economic Forum 2016.

Once plastic debris enters the marine environment, they interact with various marine species across trophic levels (Wang et al. 2020a; Guzzetti et al. 2018). MP/NPs have been found in a wide variety of marine species, including cetaceans, copepods, chaetognaths, shrimps, echinoderms, zooplankton, corals, fishes, turtles, seabirds, and mammals, causing cascading effects in the marine food web due to their small size (Botterell et al. 2019). Phagocytosis and pinocytosis are two pathways for marine organisms' uptake of MP/NPs (Allen et al. 2020). They are transported through several physiological routes and translocate mainly to the stomach, intestine, gills, digestive tract, and sometimes to the liver (Allen et al. 2020). Ingestion of MPs causes deleterious effects in marine taxa, mainly impairment, reduced feeding behavior, inhibited growth, nutrient uptake, decreased immune response, oxidative stress, cellular toxicity, pseudo-satiety sensation, fertility reduction, malnutrition, and lastly, death (Gonçalves and Bebianno 2021). Tigriopus japonicas, when exposed to polystyrene microbeads, exhibited a decrease in fecundity across two generations (Lee et al. 2013). Brachionuskoreanus ingestion with fluorescent-labeled PS nanobeads $(50 \mathrm{~nm}, 500 \mathrm{~nm}$, and $6 \mu \mathrm{m}$ ) causes increased oxidative stress and decreased growth rate, fecundity, and body size (Jeong et al. 2016). Adult oysters and blue mussels on ingestion with $50 \mathrm{~nm}$ NPs lead to a substantial decrease in embryo-larvae development and fertilization, which results in complete stagnation (Rist et al. 2019). Similarly, MPs act as vectors for Aeromonas salmonicidia (a fish bacterial pathogen), which can form biofilms and transfer to the food chain upon consumption of infected fish (Viršek et al. 2017). To investigate the anthropogenic impacts, 41 fishes were sampled from Giglio Island after refloating project of Coasta Concordia Wreck. Out of 41, 85\% of examined fish, i.e., benthonic species Phycis phycis, Scorpaena sp., and Uranoscopus scaber showed 77\%, $84 \%$, and $86 \%$ plastic particles. In comparison, benthopelagic Spondyliosoma cantharus exhibited $100 \%$ plastic particles in the gastrointestinal tract dominated by fragments, lines, and films (Avio et al. 2017). Microorganisms and fisheries habiting coral reefs are eight times more likely to be affected by plastics. MP/NP loads correlate to terrestrial dispersal into the season coral reefs. The amount of plastic objects entangled on coral reefs in the Asia-Pacific region is predicted to reach 11.1 billion, with the number expected to rise by $40 \%$ by 2025 (Lamb et al. 2018). Due to the high surface-volume ratio, hydrophobicity, and lipophilicity, MP/NPs can incorporate heavy metals $(\mathrm{Ni}, \mathrm{Pb}, \mathrm{Zn}, \mathrm{Cu}, \mathrm{Cd}$, and $\mathrm{Ti}$ ), PCBs, PAHs, POPs, phthalates, and bisphenol A on their surface (Prata 2018). Co-contamination of mercury and microplastic in marine environments causes behavioral changes and reduced swimming velocity in Dicentrarchus labrax (Barboza et al. 2018). Oryzias latipes (Japanese medaka fish), when exposed to polyethylene and chemical pollutants (PCBs, PAHs, and PBDEs), showed symptoms of tumor formation, cellular necrosis, down regulation of choriogenin (chgH) in males, and vitellogenin (VTgI) gene expression in females (Guzzetti et al. 2018). Perfluorooctane sulfonic acid and benzo[a]pyren) interact with polyethylene MPs, and are known to induce cancer in humans (O'Donovan et al. 2020). MP/NPs also function as medication delivery vectors entering marine water as medical waste or human faces (Campanale et al. 2020).

\subsection{Food web}

Micro/nanoplastics enter the food chain because of their wide availability in aquatic and terrestrial environments. MP/NPs were observed in honey, beer, poultry, salt, sugar, teabags, milk, salmon, seaweed, shrimps, and bivalves among other things (Markic et al. 2020; Cox et al. 2019; Santillo et al. 2017). According to reports, the average MP/NPs in food products is as follows: seafood $\left(1.48\right.$ items $\left.^{-1}\right)$; sugar

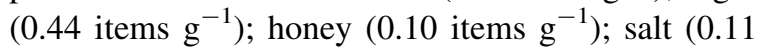
items $\left.\mathrm{g}^{-1}\right)$; alcohol (32.27 items $\mathrm{L}^{-1}$ ); bottled water (94.37 items $\left.\mathrm{L}^{-1}\right)$; and tap water (4.23 items $\mathrm{L}^{-1}$ ) (Yee et al. 2021; Zhang et al. 2020). Plastic teabags, 
bottled water, and seafood are among the sources of exposure (Kosuth et al. 2018), and unusually high MP/ NPs in fruits and vegetables have also been observed (Conti et al. 2020).On average, human beings consume 39,000 to $52,000 \mathrm{MP} / \mathrm{NPs}$ particles per year, whereas individuals who drink bottled water, in addition, consume 90,000 particles (Mason et al. 2018). MP/NPs contamination in drinking water bottles resulted in $40.1 \mathrm{mg} \mathrm{kg}^{-1}$ body-weight day ${ }^{-1}$ for adults and $87.8 \mathrm{mg} \mathrm{kg}^{-1}$ body-weight day $^{-1}$ for children (Zuccarello et al. 2019). MPs occurrence was also reported in salt between 56 and 103 particles $\mathrm{kg}^{-1}$ of salt (Seth and Shriwastav 2018).

\section{Health risk}

Plastic usage in daily human activities (drinking water bottles, soft drinks, food packaging, and medical device, etc.) increases their abundance and human health risks (Jiang et al. 2020). The major routes for MPs intake are inhalation, skin perfusion, and ingestion, whereas NPs enter organisms through physical piercing and endocytosis/phagocytosis (O'Neill and Lawler 2021). The most prevalent route of MP/NPs exposure is through contaminated food, associated with gastrointestinal consequences, including reduced epithelial permeability, localized inflammatory processes, and changes in gut microbiota composition (Campanale et al. 2020). Most European countries rely on shellfish and crustaceans as their food diet and are estimated to ingest $1800 \mathrm{MPs} / \mathrm{year}$ per person (Barboza et al. 2018). MPs were identified in the tissues of commercially cultivated bivalves, M. edulis, and Crassostrea gigas, with quantities ranging from 360.07 to 470.16 particles per gram, collected from mussel farms and supermarkets (Zhang et al. 2020; van Cauwenberghe and Janssen 2014). Rapid bronchospasm, diffuse interstitial fibrosis, inflammatory and fibrotic changes in bronchial and peribronchial tissue, and interalveolar lesions are caused by inhaling MP/NPs (Mariano et al. 2021). The accumulation of NPs by primary producers Chlamydomonas reinhardtii and Daphnia magna starts the trophic transmission of NPs in the food web (Zhu et al. 2021). The trophic transfer occurs when primary producers are eaten by secondary (Oryza sinensis) and tertiary (Zacco temminckii) consumers before being passed to humans (Zhu et al. 2021). NPs transferred from the primary producers to top consumers make morphological alterations and strongly affect their behavior and metabolism (Zhu et al. 2021).

On the other hand, MPs are unlikely to be absorbed via the skin since stratum corneum diffusion is limited to nano-sized polymers with a diameter of less than $100 \mathrm{~nm}$ (Gonçalves and Bebianno 2021). Personal and cosmetic goods, particularly in the body, include nanoplastics, as face washes are administered topically to the skin. Urea, glycerol, and -hydroxyl acids, all common constituents in body lotions, improved the nanoparticle's capacity to penetrate the skin barrier (Jatana et al. 2016). Oral administration of MP/NPs produces redox imbalance, disruption of energy homeostasis, and neurotoxicity in the gut, intestine, and kidney (Deng et al. 2017). Endocytic mechanisms allow polystyrene and PVC particles $(150 \mathrm{~nm})$ to penetrate the gut wall and end up in lymph nodes and the blood vascular system ( $\mathrm{Xu}$ et al. 2019). A significant reduction in testosterone, luteinizing hormone, and follicle-stimulating hormone was reported with mice given $40 \mathrm{~nm}$ polystyrene NPs for 35 days (Amereh et al. 2020). Recent research found $20 \mathrm{MPs}$ $(50-500 \mu \mathrm{m})$ per $10 \mathrm{~g}$ of human feces, with nine distinct plastic types (most common of which were polypropylene and polyethylene terephthalate) (Shen et al. 2019). Organochlorines are well-known endocrine-disrupting compounds that increase cytotoxicity and inflammatory response (Prata 2018). NPs affect neustonic/planktonic habitats and act as surface receptors for accumulating organochlorines (OCs) and cause toxicological effects in organisms such as Balaenoptera physalus and Cetorhinus maximus (Fossi et al. 2014).

\section{Sampling and analysis}

Organizations, namely ICES, GESAMP, UNEPMEDPOL and JPL Oceans, developed standardized methodologies on MP/NPs monitoring (GESAMP 2016).

\subsection{Sampling}

Wastewater streams, surface water, bottled water, sediments, untreated and treated tap water were collected by pumping, trawling, followed by sieving to separate MP/NPs particles of the desired size range 
(Yang et al. 2019a, b; Koelmans et al. 2019; Raju et al. 2018). Auto-sampler, surface filtration, separate pumping, and containers are employed in collecting sampling for MP/NPs quantification and characterization from wastewater streams (Fig. 4). Separate pumping and filtration processes are efficient methods for collecting wastewater due to high solids, organic matter, and sampling volume ranging from hundreds to cubic metre litres (Song et al. 2018). Neuston nets, manta trawls, etc., are often used for sampling MP/ NPs from aqueous samples (Song et al. 2018). Samples above $500 \mu \mathrm{m}$ are fractionated with a stainless-steel filter and sorted under a stereomicroscope (Yang et al. 2019a, b; Koelmans et al. 2019). For identification, samples with size fractions less than $500 \mu \mathrm{m}$ underwent enzymatic and oxidative purification. Sand samples from the shoreline identified MPs when sieved through $5 \mathrm{~mm}$ mesh followed by $2 \mathrm{~mm}$ (Ceccarini et al. 2018). Post-treated sewage sludge and anaerobically digested sludge were passed through $250 \mu \mathrm{m}$ sieve to trap MPs and later filtered through 212,63 , and $45 \mu \mathrm{m}$ sieves for particle size fractionation (Mahon et al. 2017). Samples from various WWTPs passed through the customized filtration device with an electric pump and identified MPs with

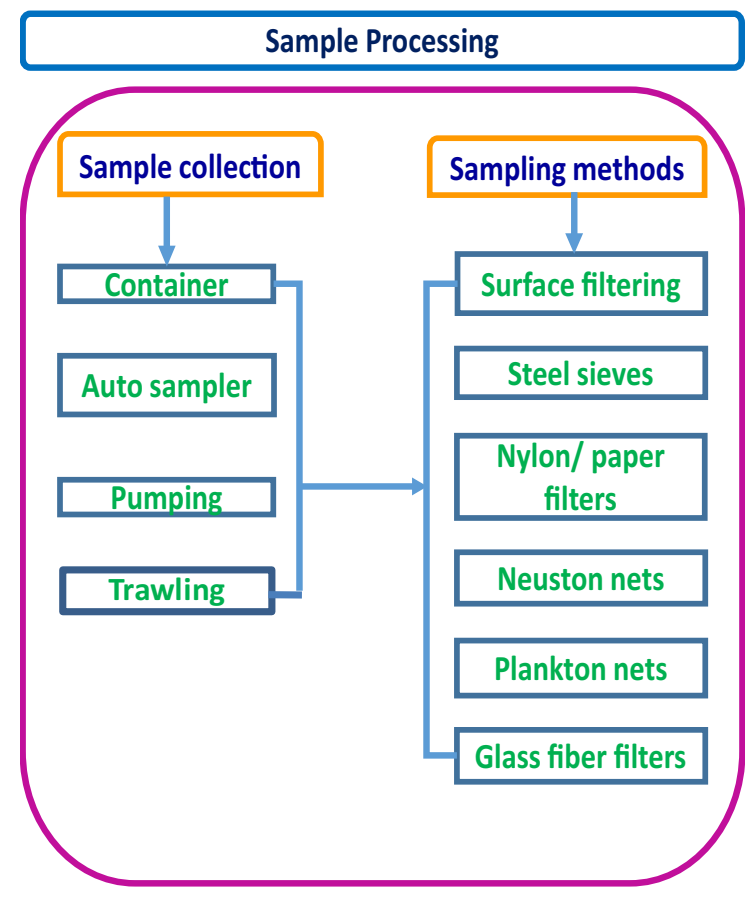

Fig. 4 Schematic representation of samplecollection and processing routesof micro/nanoplastics in the environment a particle size of $>300 \mathrm{~mm}, 100-300 \mathrm{~mm}$, and 20-100 mm (Talvitie et al. 2017; Li et al. 2021; Yang et al. 2019a, b; Cabernard et al. 2018; Song et al. 2018; Ceccarini et al. 2018; Dyachenko et al. 2017). Hermsen et al. (2018) suggested using fixatives like ethanol, formalin, or methyl aldehyde in sampling containers avoids retention of MPs. Ethanol and formalin have less effect on polymer, but it tends not to lose their characteristics (Sun et al. 2019). For NPs separation, magnetic field flow fractionation (MFFF), gel electrophoresis, and size-exclusion chromatography (SEC) were used ( $\mathrm{Li}$ et al. 2021; Nguyen et al. 2019).

\subsection{Density separation}

Density separation is also used to isolate MP/NPs from wastewater to limit their number in WWTPs (McGivney et al. 2020; Schwinghammer et al. 2020). This method separates MP/NPs from sludge, sediments, and other inorganic materials that have not been degraded during pre-treatment/breakdown (chemical or enzymatic) processes (Hermsen et al. 2018). The density of most plastics is almost equal to water, and MP/NPs particles suspended in water tend to float, making their removal process easy (Enfrin et al. 2019). High-density solutions like sodium chloride $(\mathrm{NaCl})$, sodium iodide $(\mathrm{NaI})$, potassium formate $(\mathrm{K}(\mathrm{HCOO}))$, zinc chloride $\left(\mathrm{ZnCl}_{2}\right)$, sodium tungstate dehydrates and sodium polytungstate are used in the density separation of MP/NPs (Table 2). NaI is expensive and hazardous to the environment according to the GHS classification (Enfrin et al. 2019). $\mathrm{NaCl}$ is recommended for sediment samples due to its low cost and non-toxic nature. Due to their lower density, most plastics tend to float on the surface and can be reduced up to $80 \%$ ( $\mathrm{Li}$ et al. 2021; Zhao et al. 2017). $\mathrm{ZnCl}_{2}$ is one of the inexpensive methods with a good recovery rate ( $\mathrm{Li}$ et al. 2021). $\mathrm{K}(\mathrm{HCOO})$, after utilization, can be filtered and reusable (Mahon et al. 2017). However, sodium polytungstate is relatively expensive, whereas sodium tungstate dihydrate is recommended in standardized protocols for sediments (McGivney et al. 2020; Schwinghammer et al. 2020). Canola oil was also used to separate MPs (fibres and fragments) with 92-97\% recovery (Stock et al. 2019). The dualdensity isolation mechanism for separating MP/NPs was also reported (Zhao et al. 2017). First, a higherdensity medium is used to separate plastic particles 
Table 2 Various processes involved in density separation and pre-treatment methods of micro/nanoplastics in the environment

\begin{tabular}{|c|c|c|c|c|c|c|c|}
\hline & \multicolumn{2}{|l|}{$\begin{array}{l}\text { Type of } \\
\text { Polymer }\end{array}$} & Solution & $\begin{array}{l}\text { Density } \\
\left(\mathrm{g} / \mathrm{cm}^{3}\right)\end{array}$ & Advantage & Disadvantage & References \\
\hline \multirow[t]{7}{*}{$\begin{array}{l}\text { Density } \\
\text { Separation }\end{array}$} & \multicolumn{2}{|l|}{$\mathrm{PP}, \mathrm{PE}$} & Water & 1 & $\begin{array}{l}\text { Simple; Easy to } \\
\text { operate }\end{array}$ & $\begin{array}{l}\text { Limited with } \\
\text { high-density } \\
\text { plastics and less } \\
\text { recovery rates } \\
\text { with more } \\
\text { errors }\end{array}$ & $\begin{array}{l}\text { Lv et al. (2021); Li et al. } \\
\text { (2021); Stock et al. (2019); } \\
\text { Enfrin et al. (2019); Sun } \\
\text { et al. (2019); Munno et al. } \\
\text { (2018); Lares et al. (2018); } \\
\text { Zhao et al. (2017); Coppock } \\
\text { et al. (2017); Mahon et al. } \\
\text { (2017); Löder et al. (2017); } \\
\text { Dehaut et al. (2016); Avio } \\
\text { et al. (2017) }\end{array}$ \\
\hline & \multicolumn{2}{|c|}{$\begin{array}{l}\text { Microplastics } \\
\text { with a density } \\
\text { below } 1.2 \mathrm{~g} / \\
\mathrm{cm}^{3} \text { (eg: PA, } \\
\text { PE, PP etc.) }\end{array}$} & $\mathrm{NaCl}$ & 1.2 & $\begin{array}{l}\text { Economically } \\
\text { feasible and } \\
\text { Non-toxic, } \\
\text { Easy available } \\
\text { and eco- } \\
\text { friendly }\end{array}$ & $\begin{array}{l}\text { Limited with } \\
\text { high-density } \\
\text { plastics and less } \\
\text { recovery rates } \\
\text { with more } \\
\text { errors }\end{array}$ & \\
\hline & \multicolumn{2}{|c|}{$\begin{array}{l}\text { Nylon, PVC, } \\
\text { PET }\end{array}$} & $\begin{array}{l}\text { Sodium } \\
\text { polytungstate }\end{array}$ & 1.4 & $\begin{array}{l}\text { Non-toxic and } \\
\text { Highly } \\
\text { efficient to } \\
\text { extract certain } \\
\text { high-density } \\
\text { plastics }\end{array}$ & Not specified & \\
\hline & \multicolumn{2}{|c|}{$\begin{array}{l}\text { PVC, PS, PET, } \\
\text { PE,PUR, PP }\end{array}$} & $\mathrm{NaI}$ & 1.6 & $\begin{array}{l}\text { Recovery rates } \\
\text { are very } \\
\text { high }>99 \%\end{array}$ & $\begin{array}{l}\text { Cross } \\
\text { contamination } \\
\text { (Reacts with } \\
\text { cellulose } \\
\text { matter) } \\
\text { Not eco-friendly } \\
\text { and expensive }\end{array}$ & \\
\hline & \multicolumn{2}{|c|}{$\begin{array}{l}\text { Almost all } \\
\text { plastics }\end{array}$} & $\mathrm{ZnCl}_{2}$ & 1.7 & $\begin{array}{l}\text { Easy and } \\
\text { applicable for } \\
\text { almost all } \\
\text { plastics }\end{array}$ & $\begin{array}{l}\text { High economic } \\
\text { inputs and } \\
\text { Toxic }\end{array}$ & \\
\hline & \multicolumn{2}{|c|}{$\begin{array}{l}\text { Microplastics } \\
\text { with a density } \\
\text { below } 1.8 \mathrm{~g} / \\
\mathrm{cm}^{3} \\
\text { (eg: PA, PE, PP } \\
\text { etc.) }\end{array}$} & $\begin{array}{l}\text { Potassium } \\
\text { formate }\end{array}$ & 1.9 & $\begin{array}{l}\text { More } \\
\text { microplastics } \\
\text { can be } \\
\text { extracted }\end{array}$ & Not specified & \\
\hline & Digestion & Reag & ents & & Effect on polymer & & \\
\hline \multirow[t]{2}{*}{$\begin{array}{l}\text { Pre- } \\
\text { treatment }\end{array}$} & Oxidative & \multicolumn{3}{|c|}{$\begin{array}{l}\text { Fenton reagent; } \mathrm{K}_{2} \mathrm{~S}_{2} \mathrm{O}_{8} ; 5 \% \\
\mathrm{NaClO} ; 30-35 \% \mathrm{H}_{2} \mathrm{O}_{2}\end{array}$} & \multicolumn{3}{|c|}{$\begin{array}{l}\text { Decolouration of polyethylene, PET and polyester } \\
\text { Degrades NY6 and NY66 and difficult in complete digestion of } \\
\text { biomaterials at any temperature. } \\
\text { Digestibility rates are }<95 \%\end{array}$} \\
\hline & Acid & \multicolumn{2}{|c|}{$37 \% \mathrm{HCl} ; \mathrm{H}_{2} \mathrm{SO}_{4} ; 65 \%$} & HNO3 & $\begin{array}{l}\text { Digestibility rates } \\
\text { Higher concentratic } \\
\text { significant decolo } \\
\text { Acids are Corrosiv }\end{array}$ & $\begin{array}{l}\text { Ire }>95 \% \text {. } \\
\text { of of acids cause d } \\
\text { uration of polymers } \\
\text { to NY6 and NY66 }\end{array}$ & $\begin{array}{l}\text { gradation of polymers and } \\
\text { and melts PET as well }\end{array}$ \\
\hline
\end{tabular}


Table 2 continued

\begin{tabular}{|c|c|c|}
\hline Digestion & Reagents & Effect on polymer \\
\hline \multirow[t]{2}{*}{ Alkali } & \multirow[t]{2}{*}{$10 \% \mathrm{KOH} ; \mathrm{NaOH}$} & $\begin{array}{l}\text { Higher concentrations of } \mathrm{NaOH} \text { causes partial destruction of the nylon } \\
\text { fibers, melting of the polyethylene, and colour change of plastic } \\
\text { particles. }\end{array}$ \\
\hline & & $\begin{array}{l}\mathrm{KOH} \text { at } 40{ }^{\circ} \mathrm{C} \text { is measured to be the destructive treatment of all } \\
\text { polymers }\end{array}$ \\
\hline \multirow[t]{2}{*}{ Enzymatic } & \multirow[t]{2}{*}{$\begin{array}{l}\text { Proteinase K; Trypsin; } \\
\text { Cellulose; Chitinase; Lipase } \\
\text { rtc }\end{array}$} & $\begin{array}{l}\text { Low concentration of trypsin, Proteinase } \mathrm{K} \text { etc. has higher digestion. } \\
\text { Enzymatic digestion efficiencies are } 88 \% \text { and does not effect on } \\
\text { microplastics. }\end{array}$ \\
\hline & & $\begin{array}{l}\text { The optimized concentrations can digest }>95 \% \text { in the phytoplankton of } \\
\text { seawater samples without damaging any MPs fragments }\end{array}$ \\
\hline
\end{tabular}

such as polyethylene (PE), polypropylene (PP), and polystyrene (PS) from heavier components (minerals). Second, adding calcium fluoride to a low-density solvent (pure methanol) enables selective sedimentation of plastic enabling effective recovery via centrifugation. These solvents don't harm the plastic polymers, except polypropylene, since the density is relative to solvent (Fries et al. 2013). The density separation is not ideal for larger WWTPs due to MP/ NPs, and the procedure must be done in the static mode because rushing water would disperse the particles (Stock et al. 2019).

\subsection{Pre-treatment}

Wastewater in general consists of suspended matter, sediments, solid biomass, and organic material. Sediments and solid biomass can be easily separated by picking or filtration, but the complexity comes with suspended and organic matter. Heating of the sample at higher temperature damages MP/NPs due to degradation or mechanical friction (Sun et al. 2019). Prior digestion, samples need to be treated due to high concentrations of organic matter or inorganic solids materials. The biofilm formation on MPs with smaller size $(0.063 \mathrm{~mm})$ is an alternative to the digestion process and enables recovery to some extent. However, this method has many drawbacks like inefficiency for large-scale samples, cost-effectiveness, time-consuming, and limited recovery (Felsing et al. 2018; Rummel et al. 2017). Organic content in the waste samples is pre-treated/digested mostly by chemical digestion and enzymatic digestion.

\subsubsection{Chemical}

The chemical digestion methods can be classified into acid, alkali, and oxidation treatments. Acidic digestion was performed to reduce organic matter in the samples using $\mathrm{H}_{2} \mathrm{SO}_{4}, \mathrm{HNO}_{3}$, and $\mathrm{HCl}$ ( $\mathrm{Li}$ et al. 2021; Avio et al. 2017). A maximum of $98 \%$ degradation was noticed using $\mathrm{HNO}_{3}$ compared to other acids. It has a disadvantage with polymers PS and PE since these particles get agglutinated during dissolution. $\mathrm{HCl}$ is less preferred due to its inefficiency in destroying bulk organic matter (Cole et al. 2014), while $\mathrm{H}_{2} \mathrm{SO}_{4}$ deform and degrade the plastic along with the organic compounds. Alkali digestion was carried out using strong base solutions like $\mathrm{NaOH}$ or $\mathrm{KOH}$. The use of $1 \mathrm{M} \mathrm{NaOH}$ shows the efficiency of $\geq 90 \%$ organic digestion (Cole et al. 2014). Further increase in molarity, polymers like PE, PET, PVC, and cellulose acetate start degrading into simple forms (Munno et al. 2018). Upon exposure for a longer time, $\mathrm{NaOH}$ degrades the MPs, but KOH retains them from degradation except for cellulose acetate (Dehaut et al. 2016). Oxidizing digestion is one of the commonly used methods for digesting organic matter. $\mathrm{NaClO}$ and $\mathrm{H}_{2} \mathrm{O}_{2}(30 \%)$ are efficient oxidizers ( $\mathrm{Li}$ et al. 2021; Sun et al. 2019; Lares et al. 2018). Fenton reagent $\left(\mathrm{FeSO}_{4} / \mathrm{H}_{2} \mathrm{O}_{2}\right)$ is generally referred to as an advanced oxidizing agent used in digesting soil organic matter, compost, and large volumes of wastewater (Tagg et al. 2017; Masura et al. 2015). The reagent degrades MPs with less than $5 \mathrm{~mm}$ and facilitates biological samplings (gut or tissues) (Tagg et al. 2017). MPs can be recovered up to $70 \%$ when digested with $30 \% \mathrm{H}_{2} \mathrm{O}_{2}$ for seven days (Liu et al. 2019). Further increase in $\mathrm{H}_{2} \mathrm{O}_{2}$ concentration, 
deformation of plastics was observed. So, using a lower concentration of $\mathrm{H}_{2} \mathrm{O}_{2}$ and Fenton reagent is recommended with an exposure time of 12-24 h (Munno et al. 2018; Zhao et al. 2017). Recently, a metal-doped particle approach was adopted for NPs extraction. Pd-doped nanoplastic particles were spiked into ultrapure water with microwave-assisted acid digestion to assess the presence of NPs (Hildebrandt et al. 2020).

\subsubsection{Enzymatic}

Enzymatic degradation is the alternative method for chemical digestion for removing organic matter. It digests biological/aquatic tissues and organic matter in the waste samples. Enzymes such as cellulose, chitinase, protease, trypsin, papain, collagenase, and lipase were used in various studies (Sun et al. 2019; Courtene-Jones et al. 2017). Enzymatic digestion using protease showed $>97 \%$ degradation (Cole et al. 2014). Löder et al. (2017) conducted experiments using a combination of enzymes. It modified the process and incubation conditions, where the whole degradation procedure of organic matter could not take more than one week. Utilizing enzymes for MP/ NPs digestion is safe, but this process is limited to low quantity samples as it is an expensive process. This process does not apply to large-scale treatment as each enzyme requires its optimum $\mathrm{pH}$ for its functioning and digestion of samples (Stock et al. 2019; Löder et al. 2017).

\subsection{Identification}

Detection and predicting the formation of MP/NPs in wastewater is complex to perform (Zhao et al. 2017). Various analytical protocols to identify the size, quantity, and types of plastic particles have been used (Table 3). Sieve pattern and size create a primary cutoff for particles present in the samples (Li et al. 2021; Lv et al. 2019; Magnusson and Norén 2014). The simple method for identifying plastic matter is the 'hot-point test' where heated needle, when placed in the sample, plastic gets melted and masks over the needle, which will not permit identifying the nature and type of plastic (Hebner and Maurer-Jones 2020). Transmission electron microscopy (TEM), Field emission scanning electron microscopy (FE-SEM), dynamic light scattering (DLS), and multi-angle light scattering (MALS) with pyrolysis detect particles of size $(10 \mathrm{~nm})$ and provide finite pictures/patterns. Energy-dispersive X-ray spectroscopy (EDX) coupled with FE-SEM reveals the elemental composition of MP/NPs (Li et al. 2021; Sun et al. 2019; Long et al. 2019; Corcoran et al. 2009). Fourier transform infrared spectroscopy (FTIR), focal plan array-based systems (FPA), micro-FTIR, and Raman spectroscopy are used to identify functional groups of polymers (Sun et al. 2019; Duemichen et al. 2015; Fries et al. 2013), while the structural architect of plastics can be identified using thermogravimetric analysis-gas chromatography-mass spectrometry (TGA-GC-MS), pyrolysisgas chromatography-mass spectrometry (GC/MS) and thermogravimetric analysis (TGA) with thermal desorption-gas chromatography-mass spectrometry (TED-GC/MS) (Li et al. 2021; Lv et al. 2019; Duemichen et al. 2015). However, these techniques are sensitive to analyzing MP/NPs with impurities. Prior pre-treatment processes like wet peroxide oxidation, enzymatic digestion, and oxidizing agents facilitate the detection of MP/NPs. For nanoplastics, identification through these methods becomes more challenging when the sample size exceeds $500 \mathrm{~mm}$, and the weight is less than $10 \mathrm{mg}$.

\subsubsection{Microscopy}

Identification of MPs using a microscope can be classified mainly by Optical/visual microscopy, Scanning electron microscope (SEM), and Transmission electron microscopy (TEM). The plastic particles were identified based on surface, and chemical structures as MPs do not shine and exhibit ductility/ malleability under physical stress (Zhao et al. 2017). MPs collected from various wastewater streams were passed through a filtered mesh and categorized into wires, needles, fibres, clusters, fragments, irregular partials, etc., with two or three-dimensional shapes (Hebner and MaurerJones 2020). However, visual observation of MPs is difficult due to the lower magnification factor of microscopes. MPs are size constrained and have a high error ratio (Uurasjärvi et al. 2020; Lv et al. 2019). Filtered MPs from the secondary wastewater treatment plants were observed under stereo-microscope, confirming bead-shaped MPs with $87 \%$ recovery (Dyachenko et al. 2017). Waste sludge samples free of organic matter observed fibres and particles when visualized under a digital optical microscope with 
Table 3 Various methods of identification and characterization of micro/nanoplastics in environmental samples

\begin{tabular}{|c|c|c|c|c|c|}
\hline Processes & Technique & $\begin{array}{l}\text { Range/ } \\
\text { Limits }\end{array}$ & Advantage & Drawbacks & References \\
\hline \multirow[t]{3}{*}{$\begin{array}{l}\text { Pre- } \\
\text { concentration }\end{array}$} & $\begin{array}{l}\text { Membrane filtration/ } \\
\text { Ultra-filtration }\end{array}$ & $\begin{array}{l}>10 \mathrm{~nm} \\
5-50 \mathrm{~nm}\end{array}$ & $\begin{array}{l}\text { Easy and cheap } \\
\text { process, } \\
\text { Process larger } \\
\text { volumes } \\
\text { No sample damage/ } \\
\text { aggregation }\end{array}$ & $\begin{array}{l}\text { Frequent interaction } \\
\text { with membrane. } \\
\text { Low flow rates with } \\
\text { small pores and } \\
\text { less volumes }\end{array}$ & $\begin{array}{l}\text { Li et al. (2021); } \\
\text { Schwinghammer et al. } \\
\text { (2020); McGivney } \\
\text { et al. (2020); } \\
\text { Uurasjärvi et al. } \\
\text { (2020); Lv et al. } \\
\text { (2019); Schwaferts } \\
\text { et al. (2019); Xu et al. } \\
\text { (2019); Lv et al. } \\
\text { (2019); Erni-Cassola } \\
\text { et al. (2017); } \\
\text { Ziajahromi et al. } \\
\text { (2017); Shim et al. } \\
\text { (2016); Fries et al. } \\
\text { (2013) }\end{array}$ \\
\hline & Dialysis & $5-50 \mathrm{~nm}$ & $\begin{array}{l}\text { Performed at mild } \\
\text { condition }\end{array}$ & $\begin{array}{l}\text { Slow process and } \\
\text { requires large } \\
\text { volume of counter } \\
\text { dialyzing medium }\end{array}$ & \\
\hline & $\begin{array}{l}\text { Ultracentrifugation } \\
\text { and Analytical ultra- } \\
\text { centrifugation }\end{array}$ & $1 \mathrm{~nm}-1 \mu \mathrm{m}$ & $\begin{array}{l}\text { Simple and easy } \\
\text { operation } \\
\text { Can provide more } \\
\text { information on } \\
\text { MPs/NPs } \\
\text { Very effective in } \\
\text { separation }\end{array}$ & $\begin{array}{l}\text { Operated at harsh } \\
\text { conditions and no } \\
\text { separation from } \\
\text { particulate matrix } \\
\text { Difficult to obtain } \\
\text { complete } \\
\text { separation }\end{array}$ & \\
\hline \multirow[t]{5}{*}{$\begin{array}{l}\text { Separation } \\
\text { techniques }\end{array}$} & Solvent evaporation & $\begin{array}{l}\text { All } \\
\text { particulates }\end{array}$ & Easy and economic & $\begin{array}{l}\text { Requires more } \\
\text { energy } \\
\text { Difficult to remove } \\
\text { dissolved matter }\end{array}$ & \\
\hline & $\begin{array}{l}\text { Asymmetric Flow } \\
\text { Field Fractionation }\end{array}$ & $1 \mathrm{~nm}-1 \mu \mathrm{m}$ & $\begin{array}{l}\text { There is no } \\
\text { stationary phase } \\
\text { and done by online } \\
\text { monitoring }\end{array}$ & $\begin{array}{l}\text { Difficult in } \\
\text { operation, } \\
\text { Interaction with } \\
\text { membrane and } \\
\text { Steric inversion }\end{array}$ & \\
\hline & $\begin{array}{l}\text { Size Exclusion } \\
\text { Chromatography }\end{array}$ & $1-100 \mathrm{~nm}$ & $\begin{array}{l}\text { Fixed with Coupled } \\
\text { detectors }\end{array}$ & $\begin{array}{l}\text { Operated at small } \\
\text { range of samples } \\
\text { and stationary } \\
\text { phase }\end{array}$ & \\
\hline & $\begin{array}{l}\text { High Performance } \\
\text { Liquid } \\
\text { Chromatography }\end{array}$ & $1-40 \mathrm{~nm}$ & $\begin{array}{l}\text { Fixed with Coupled } \\
\text { detectors }\end{array}$ & $\begin{array}{l}\text { Operated at small } \\
\text { range of samples } \\
\text { and stationary } \\
\text { phase }\end{array}$ & \\
\hline & $\begin{array}{l}\text { Capillary } \\
\text { Electrophoresis }\end{array}$ & $5-500 \mathrm{~nm}$ & $\begin{array}{l}\text { Fast and high } \\
\text { separation rates } \\
\text { Fixed with Coupled } \\
\text { detectors }\end{array}$ & $\begin{array}{l}\text { External charge } \\
\text { required, } \\
\text { Electrolyte/surface } \\
\text { modification } \\
\text { Might damage } \\
\text { sample by } \\
\text { Interaction with } \\
\text { capillary/clogging }\end{array}$ & \\
\hline
\end{tabular}


Table 3 continued

\begin{tabular}{|c|c|c|c|c|c|}
\hline Processes & Technique & $\begin{array}{l}\text { Range/ } \\
\text { Limits }\end{array}$ & Advantage & Drawbacks & References \\
\hline & $\begin{array}{l}\text { Hydrodynamic } \\
\text { Chromatography }\end{array}$ & $\begin{array}{l}5 \mathrm{~nm}- \\
1.2 \mu \mathrm{m}\end{array}$ & $\begin{array}{l}\text { Minimal interaction } \\
\text { with stationary } \\
\text { phase }\end{array}$ & $\begin{array}{l}\text { Application is very } \\
\text { less }\end{array}$ & \\
\hline \multirow[t]{10}{*}{$\begin{array}{l}\text { Characterization } \\
\text { technique }\end{array}$} & $\begin{array}{l}\text { Dynamic Light } \\
\text { Scattering (DLS) } \\
\text { (Size (dh), PSD, } \\
\text { aggregation } \\
\text { behaviour) }\end{array}$ & $\begin{array}{l}1 \mathrm{~nm}-3 \mu \mathrm{m} \\
\text { conc. } 10^{-6} \text { to } \\
10^{-1}\end{array}$ & $\begin{array}{l}\text { Easy, fast and } \\
\text { economic } \\
\text { Process is In- situ, } \\
\text { Non-invasive, } \\
\text { Aggregation and } \\
\text { direct coupling }\end{array}$ & $\begin{array}{l}\text { Large particles, } \\
\text { Polydispersity with } \\
\text { complex matrix, } \\
\text { Non-spherical } \\
\text { particles }\end{array}$ & \\
\hline & $\begin{array}{l}\text { Electrophoretic Light } \\
\text { Scattering (ELS) } \\
\text { (Surface charge, } \\
\text { stability) }\end{array}$ & $1 \mathrm{~nm}-3 \mu \mathrm{m}$ & $\begin{array}{l}\text { Fast and cheap } \\
\text { Non-invasive }\end{array}$ & $\begin{array}{l}\text { Involves Electro- } \\
\text { osmotic effect and } \\
\text { Sensitive to } \\
\text { environment }\end{array}$ & \\
\hline & $\begin{array}{l}\text { MALS (Size (dg), } \\
\text { PSD) }\end{array}$ & $10-1000 \mathrm{~nm}$ & $\begin{array}{l}\text { Fixed with Coupled } \\
\text { detectors }\end{array}$ & $\begin{array}{l}\text { Prior sample } \\
\text { preparation is done, } \\
\text { requires neat and } \\
\text { clear samples }\end{array}$ & \\
\hline & $\begin{array}{l}\text { Laser Diffraction (LD) } \\
\quad(\text { Size })\end{array}$ & $\begin{array}{l}10 \mathrm{~nm}- \\
10 \mathrm{~mm}\end{array}$ & $\begin{array}{l}\text { Measures large size } \\
\text { range }\end{array}$ & Only spherical model & \\
\hline & & & $\begin{array}{l}\text { Process is easy, fast } \\
\text { and automated }\end{array}$ & & \\
\hline & $\begin{array}{l}\text { Nanoparticle Tracking } \\
\text { Analysis (NTA) } \\
\text { (Size (dh), PSD, } \\
\text { number } \\
\text { concentration) }\end{array}$ & $30 \mathrm{~nm}-2 \mu \mathrm{m}$ & $\begin{array}{l}\text { Better with } \\
\text { polydisperse } \\
\text { samples, complex, } \\
\text { media, Particle } \\
\text { corona }\end{array}$ & $\begin{array}{l}\text { Complexity in } \\
\text { operation }\end{array}$ & \\
\hline & $\begin{array}{l}\text { FPA-FT-IR } \\
\text { (Vibrational } \\
\text { spectrum, Pigments, } \\
\text { Additives, Ageing) }\end{array}$ & $>10 \mathrm{~mm}$ & $\begin{array}{l}\text { Non-destructive and } \\
\text { Automated process }\end{array}$ & $\begin{array}{l}\text { Not applicable for } \\
\text { single sub } \mu \text { - and } \\
\text { nanoplastic } \\
\text { Easy interference } \\
\text { from water takes } \\
\text { place }\end{array}$ & \\
\hline & $\begin{array}{l}\text { ATR-FT-IR; AFM-IR } \\
\text { (Spectrum, imaging) }\end{array}$ & $>50 \mathrm{~nm}$ & $\begin{array}{l}\text { Advanced, Simple } \\
\text { and fast } \\
\text { performing method } \\
\text { AFM-IR Spectrum, } \\
\text { imaging }>50 \mathrm{~nm} \text {, } \\
\text { High resolution } \\
\text { and Chemical } \\
\text { imaging }\end{array}$ & $\begin{array}{l}\text { Slow and covers } \\
\text { small area }\end{array}$ & \\
\hline & $\begin{array}{l}\text { Raman } \\
\text { Microspectroscopy } \\
\text { (Fingerprint } \\
\text { spectrum, Pigments, } \\
\text { Additives) }\end{array}$ & $\begin{array}{l}>0.5 \mathrm{~mm} \\
\text { Bulk }\end{array}$ & $\begin{array}{l}\text { Non-destructive, } \\
\text { Easy sample } \\
\text { preparation, Fast } \\
\text { and no interference } \\
\text { from water }\end{array}$ & $\begin{array}{l}\text { Works on } \\
\text { Fluorescence }\end{array}$ & \\
\hline & $\begin{array}{l}\text { XPS (Binding energies } \\
\text { of orbitals) }\end{array}$ & Bulk & $\begin{array}{l}\text { Surface scanning } \\
\text { and measurement }\end{array}$ & UHV and Laborious & \\
\hline
\end{tabular}


Table 3 continued

\begin{tabular}{|c|c|c|c|c|c|}
\hline Processes & Technique & $\begin{array}{l}\text { Range/ } \\
\text { Limits }\end{array}$ & Advantage & Drawbacks & References \\
\hline \multirow{8}{*}{ Imaging studies } & $\begin{array}{l}\text { Py-CG-MS (Mass } \\
\text { Polymer type } \\
\text { Additives) }\end{array}$ & $\begin{array}{l}\text { Bulk } \\
\text { Limit: ng- } \\
\quad \text { mg }\end{array}$ & $\begin{array}{l}\text { Measurement with } \\
\text { matrix, Fast, } \\
\text { Higher sample } \\
\text { masses can be } \\
\text { done }\end{array}$ & $\begin{array}{l}\text { Dependent on type of } \\
\text { polymer, Dry } \\
\text { sample needed } \\
\text { Prior sample } \\
\text { preparation is } \\
\text { necessary }\end{array}$ & \\
\hline & $\begin{array}{l}\text { Optical Microscopy } \\
\text { and Fluorescence } \\
\text { Microscopy (Size, } \\
\text { shape, morphology) }\end{array}$ & $>1 \mu \mathrm{m}$ & $\begin{array}{l}\text { Non-destructive, } \\
\text { Cheap, easy to } \\
\text { handle } \\
\text { Operated at sub- } \\
\text { diffraction variants }\end{array}$ & $\begin{array}{l}\text { Limited Diffraction, } \\
\text { Environmental } \\
\text { plastic is not } \\
\text { fluorescent }\end{array}$ & \\
\hline & $\begin{array}{l}\text { AFM (Size, shape, } \\
\text { topography, } \\
\text { aggregation) }\end{array}$ & $>0.1 \mathrm{~nm}$ & $\begin{array}{l}\text { High resolution and } \\
\text { AFM-IR } \\
\text { TERS and liquid }\end{array}$ & $\begin{array}{l}\text { High resolution, } \\
\text { AFM-IR, TERS } \\
\text { and done in liquid }\end{array}$ & \\
\hline & $\begin{array}{l}\text { STM; SEM (Size, } \\
\text { shape, surface } \\
\text { morphology, } \\
\text { aggregation) }\end{array}$ & $>1 \mathrm{~nm}$ & $\begin{array}{l}\text { High resolution } \\
\text { imaging }\end{array}$ & $\begin{array}{l}\text { Conductive samples, } \\
\text { Slow and covers } \\
\text { small area } \\
\text { Prior sample } \\
\text { preparation is } \\
\text { involved and has } \\
\text { charge effect }\end{array}$ & \\
\hline & $\begin{array}{l}\text { TEM (Size, shape, } \\
\text { aggregation, } \\
\text { imaging) }\end{array}$ & $<1 \mathrm{~nm}$ & $\begin{array}{l}\text { High resolution } \\
\text { imaging, Precise } \\
\text { size information } \\
\text { can be produced }\end{array}$ & $\begin{array}{l}\text { Quantification is } \\
\text { difficult } \\
\text { Prior sample } \\
\text { preparation is } \\
\text { involved and } \\
\text { expensive process }\end{array}$ & \\
\hline & $\begin{array}{l}\text { EDS (Elemental } \\
\text { composition) }\end{array}$ & $\mathrm{nm}$ range & $\begin{array}{l}\text { Complementary to } \\
\text { SEM, } \\
\text { measurement of all } \\
\text { elements }\end{array}$ & $\begin{array}{l}\text { Few Elemental } \\
\text { information is not } \\
\text { given }\end{array}$ & \\
\hline & $\begin{array}{l}\text { Confocal Laser } \\
\text { Scanning } \\
\text { Microscope } \\
\text { (CLSM); Near-field } \\
\text { Scanning Optical } \\
\text { Microscopy } \\
\text { (NSOM) (Size, } \\
\text { shape, location in) }\end{array}$ & $>1 \mu \mathrm{m}$ & $\begin{array}{l}\text { Non-destructive } \\
\text { Fluorescence } \\
\text { imaging }\end{array}$ & $\begin{array}{l}\text { Covers small area } \\
\text { and Diffraction } \\
\text { limit }\end{array}$ & \\
\hline & $\begin{array}{l}\text { Environmental } \\
\text { scanning Electron } \\
\text { Microscopy (ESEM) } \\
\text { (Size, shape, } \\
\text { imaging, surface } \\
\text { morphology) }\end{array}$ & $>0.1 \mathrm{~nm}$ & $\begin{array}{l}\text { Wet samples can be } \\
\text { done at } \\
\text { environmental } \\
\text { conditions }\end{array}$ & $\begin{array}{l}\text { Reduced in } \\
\text { resolution }\end{array}$ & \\
\hline
\end{tabular}

magnification up to $1000 \mathrm{X}$ using built-in software (Lares et al. 2018). Particles with shapes such as round, flat and oval fibres have a twisted, layered, and tapered nature. Hebner and Maurer-Jones (2020) conducted experiments to observe MPs photo-degradability in simulated moving water systems and noticed 
cracks in polymer linear or structural alignments irrespective of their thickness upon exposure to UV light. Distinguishing the difference between transparent, pale-colored MPs and natural polymers (cellulose and fibrils) microscopy requires higher magnification (Dris et al. 2015; Magnusson and Norén 2014). Dyes such as Rose Bengal, Oil red EGN, Eosin B, Hostasol Yellow3G, fluorescein, safranine, isophosphate, and Nile Red are used for staining MP/NPs (Lv et al. 2019; Ziajahromi et al. 2017; Shim et al. 2016). Nile Red is used to identify MPs, i.e., polyethylene, polypropylene, polystyrene, polycarbonate, polyurethane, nylon particles, and poly (ethylene-vinyl acetate) with sizes ranging from $20 \mu \mathrm{m}$ to $1 \mathrm{~mm}$. Its fluorescence is stable for two months and is mostly used for marine and environmental pollutants (Lv et al. 2019; Ziajahromi et al. 2017). Rose-Bengal solution (4,5,6,7tetrachloro-20,40,50,70-tetraiodo-fluorescein) is used to differentiate natural fibres and MPs since the stain gets adsorbed only by natural polymers and allows easy visual separation (Lv et al. 2019). Karakolis et al. 2019 carried out their experiments by staining more than ten fluorescent dyes on plastics, and excitation and emission colours were studied using fluorescence microscopy. Application of dyes could identify MPs in the micrometre to nano scale level (Karakolis et al. 2019).

Scanning electron microscopy (SEM)is used to characterize the surface topography of MPs. The pretreated polymers samples were first coated with gold (Long et al. 2019; Corcoran et al. 2009). SEM analysis showed the dominant shapes like fragments, pellets, and fibres with average particle diameters of $11 \mathrm{~mm}$ from sediments and $130 \mathrm{~mm}$ from water suspensions, including polypropylene, polyethylene, polystyrene, and polyethylene terephthalate (Long et al. 2019). Transmission electron microscopy (TEM) effectively visualizes NPs for less amorphous particles; simplified sample preparation to electron microscopy and heavymetal stains may be necessary (Hebner and MaurerJones 2020). By combining the Brownian motion properties, the degradation studies of NPs can be analyzed effectively (Hildebrandt et al. 2020).

\subsubsection{Elemental composition}

The elemental analysis gives the individual composition of elements, whereas CHNSO analysis predicts only carbon, hydrogen, nitrogen, sulfur, and oxygen ratios present in the sample. However, detection of MPs could be difficult if sampling matter contains impurities or organic compounds and can be analyzed only by comparing with standard polymers ( $\mathrm{Li}$ et al. 2021; Sun et al. 2019). Energy-dispersive X-ray spectroscopy (EDS) was used to assess the elemental composition of MPs based on diffraction and reflection of radiation emitted from MP/NPs surfaces (Sun et al. 2019; Fries et al. 2013; Dubaish and Liebezeit 2013). Fries et al. (2013) applied this technique to identify the inorganic plastic additives (IPAs) present in the samples. The elements such as aluminum, zinc, sulfur, barium, and titanium dioxide nanoparticles $\left(\mathrm{TiO}_{2}-\mathrm{NPs}\right)$ were detected in marine (Fries et al. 2013). $\mathrm{TiO}_{2}$-NPs are formed due to the degradation of polymer- $\mathrm{TiO}_{2}$ composites in the marine environment.

\subsubsection{Fourier transforms infrared (FTIR) spectroscopy}

Fourier transforms infrared (FTIR) spectroscopy is used to detect MP/NPs chemical constituents/moieties (carbon-linked substituents) of MP/NPs in wastewater, sediments, and biota samples. It aids in the identification of plastic polymer particles by comparing their characteristic infrared spectra of carbon attached functional groups to reference spectral libraries, where each characteristic peak corresponds to chemical connections between atoms (Schwinghammer et al. 2020; McGivney et al. 2020; Zhang et al. 2016; Murphy et al. 2016). Cincinelli et al. 2017 identified rayon, polyamide, and semi-synthetic cellulose in gastrointestinal fish tracks using FTIR. Uurasjärvi et al. (2020) identified polyethylene, polypropylene, polymethyl methacrylate, polyvinylchloride, polyethylene terephthalate, and polystyrene in surface waters of lake samples. Lares et al. (2018) followed FTIR spectroscopic approach to confirm the presence of plastics and non-plastic organic particles (cellulose) in wastewater sludge. However, it is labor-intensive and needs sample preparation before identification. Attenuated total reflection FTIR spectroscopy (ATR) $\mu$-FTIR can detect irregular shaped and scattered MPs effectively than FTIR (Hidalgo-Ruz et al. 2012). Hebner and Maurer-Jones. (2020) conducted their studies to assess the photo-oxidation of plastic fragments collected from the North Pacific Gyre sample using (ATR) $\mu$ FTIR spectra and compared them against the spectral 
library. Carbonyl content was seen at the maximum value of $1700-1800 \mathrm{~cm}^{-1}$. Chen et al. (2019) analyzed synthetic PVC MPs exposed to light and UV radiation using ATR-FTIR. PVC polymer has a characteristic absorption peak at $600-700 \mathrm{~cm}^{-1}$ region associated with $\mathrm{C}-\mathrm{Cl}$ stretching vibration. Upon UV irradiation, $\mathrm{C}-\mathrm{Cl}$ bonds at 613 and $711 \mathrm{~cm}^{-1}$ were decreased and replaced by $\mathrm{C}=\mathrm{C}$ or $\mathrm{C}=\mathrm{O}$ bonds resulting in dehydrochlorination of $\mathrm{PVC}$. Similarly, Dyachenko et al. (2017) examined MPs from secondary wastewater treatment plant (WWTP) effluent using (ATR) FTIR spectrometer combined with continuum microscope in transmission mode. Polyoctadecyl methacrylate, amides, polyacrylonitrile, polyethylene, and non-plastic cellulosic cotton were detected compared with library references. Focal plane array (FPA) detector-based micro-FTIR imaging could detect MPs with sizes smaller than $20 \mu \mathrm{m}$ (Schwinghammer et al. 2020; McGivney et al. 2020; Lv et al. 2019; Tagg et al. 2017). Mintenig et al. (2017) used FPA-based transmission micro-FTIR to identify MPs in wastewater and sludge samples, limiting fibre size $(10-20 \mu \mathrm{m})$ and lateral resolution. $\mathrm{Xu}$ et al. (2019) collected 68 influent and 72 effluent samples from WWTPs and, upon analysis, found 112 plastics of 14 different types, which includes polyethylene (PE), polyamide (PA), polypropylene(PP), polystyrene (PS), polyethylene terephthalate (PET), rayon, polyvinyl chloride (PVC), poly methylmethacrylate (PMMA), rubber, polyethylene and polyether urethane (PU), polypropylene copolymer (PE-PP), acrylonitrile styrene copolymer (AS) and polyacrylate.

\subsubsection{Raman spectroscopy}

Raman spectroscopy analyzes MPs based on the inelastic scattering of light and delivers the evidence of chemical compounds in the form of molecular vibrations by a spectrum. Plastic particles of size less than $1 \mu \mathrm{m}$ are detected with better response and reliability to other non-polar functional groups, and it is unaffected towards signals caused by $\mathrm{H}_{2} \mathrm{O}$ and atmospheric $\mathrm{CO}_{2}$ (Schwinghammer et al. 2020; McGivney et al. 2020; Li et al. 2018; Zhao et al. 2017; Hidalgo-Ruz et al. 2012). Raman spectroscopy linked with a microscope favors robust and nonpresumptive identification of plastic components with various sizes ( $\mathrm{Lv}$ et al. 2019). Raman spectroscopy was performed with excitation at $455-532 \mathrm{~nm}$ on gold-coated polycarbonate filters or silicon filters (Kelkar et al. 2019; Schymanski et al. 2018). Several studies often used excitation at near-infrared (NIR, $785 \mathrm{~nm}$ ) with laser intensity of 5-7 $\mathrm{mW}$ and integration times of 15-30 s in the wavelength range between 200 and $3000 \mathrm{~cm}^{-1}$ to identify MPs without deformation and compared with Raman library ( $\mathrm{Li}$ et al. 2021; Cabernard et al. 2018; Zhao et al. 2017; Hidalgo-Ruz et al. 2012). Cole et al. (2014) suggested coherent anti-Stokes Raman scattering (CARS) microscopy based on confocal laser scanning microscopy (CLSM) and a synchronized dual-wavelength picosecond laser source. It can localize polymeric units in biological tissues with subcellular precision and gives spectral signals, but this process is limited in sensing the fluorescence samples. In such cases, samples free from fluorescence are recommended for Raman measurements (Sun et al. 2019; Li et al. 2021). MicroRaman spectroscopy for High-density polyethylene (HDPE), Polypropylene, Polystyrene polymers before and after chlorine disinfection during sterilization and detected changes in Raman intensities by total loss of existing Raman peaks and emergence of new chemical bonds resulting aggressive effect of chlorine during water treatment (Kelkar et al. 2019). HDPE has prominent Raman peaks at $1064 \mathrm{~cm}^{-1}, 1130 \mathrm{~cm}^{-1}$, $1295 \mathrm{~cm}^{-1}$, and $1416 \mathrm{~cm}^{-1}$. A shift was noted with increased chlorine dosage, and a new chlorine carbon bond peak at $678 \mathrm{~cm}^{-1}$ was detected. Polypropylene did not show any degradation effect on chlorination, and no new bonds formation was seen in Raman spectra. While in Polystyrene, new intense Raman peaks at $400 \mathrm{~cm}^{-1}, 445 \mathrm{~cm}^{-1}$, and $348 \mathrm{~cm}^{-1}$ were observed due to the oxidative stress created by excessive chlorination. Long et al. (2019) performed micro-Raman spectroscopic analysis for WWTPs and reported the presence of plastics such as $21 \%$ polyethylene, $31.6 \%$ polypropylene, $10.1 \%$ polystyrene, $7.5 \%$ polyethylene terephthalate, and $9.2 \%$ propylene copolymer. Zada and co-workers used Stimulated Raman scattering (SRS) microscopy and worked on coherent interaction of two separate laser beams with vibrational levels to identify MPs. Different polymers such as polypropylene, high-density polyethylene, polyamide 6,6 , and polyethylene terephthalate are common in environmental or consumer products. (Li et al. 2021; Schwinghammer et al. 2020; McGivney et al. 2020; Zada et al. 2018). Zhao 
et al. (2017) identified 11 chemical matrices including 6 polymers, 5 plastic additives, and pigments 100 to $500 \mathrm{~mm}$ in size from marine sediments using Raman microscopy.

\subsubsection{Mass spectroscopy}

Some of the commonly reported analyses for MP/NPs identification are $s$ liquid chromatography (LC), gas chromatography coupled with mass spectrometry (GC-MS), liquid chromatography-mass spectrometry (LC-MS), and Pyrolysis- gas chromatography-mass spectrometry GC-MS (Py-GC/MS) (Sun et al. 2019; Nguyen et al. 2019). Among them, the Pyrolysis GC/ MS technique gained much attention in recent years as GC-MS, LC-MS analytical methods consist of multiple steps such as solvent extraction, filtration, and sample preparation before chromatographic injection, which are time-consuming processes ( $\mathrm{Li}$ et al. 2021; Sun et al. 2019; Lv et al. 2019). In the Pyrolysis GC/ MS technique, samples were analyzed by injecting MP/NPs directly into the pyrolyzer, preventing contamination during sample preparation by improved analytical efficiency (Nguyen et al. 2019; Schwinghammer et al. 2020; McGivney et al. 2020). Hermabessiere et al. (2018) worked extensively on PyGC/MS method and determined the limit of detection (LOD) values for eight commercial plastics, i.e., polyethylene (PE), polystyrene (PS), polypropylene (PP), polycaprolactam (PA-6), polyethylene terephthalate (PET), polycarbonate (PC), poly(methyl methacrylate) (PMMA), and unplasticized polyvinyl chloride (uPVC). They developed LOD standards ranging from $1 \mu \mathrm{g}$ and applied them to environmental samples from beach sediments, surface seawater, and organisms. The average of all obtained masses was calculated by using intensity $(\mathrm{h})$, time $(\mathrm{t})$, and response factor (R) (Hermabessiere et al. 2018).

Response factor $(\mathrm{R})=$ Weight $/$ Height

Limit of detection (LOD) $=3 \times \mathrm{R} \times \mathrm{H}_{20 \mathrm{FWHM}}$

Fries et al. (2013) conducted experiments on MPs and bound additives in the marine environment using Pyr-GC/MS. Pyrolysis results selected from standard polymers showed the presence of polystyrene, polypropylene, polyethylene, polyamide, chlorinated and chlorosulfonated polyethylene, diethyl phthalate, diethylhexyl phthalate, 2,4-di-tert-butylphenol, etc. from the analyzed samples. However, environmental samples contain a mixture of complex structured molecules where the difficulty arises in determining the exact polymer upon pyrolysis. Duemichen et al. (2015) used thermogravimetric analysis (TGA) with thermal desorption- gas chromatography-mass spectrometry (TED-GC/MS) for handling the complex structured environmental samples of soil suspended solids of wastewater and identified mostly PE along with PS, PET, PS, and polyamide 6. NPs with lower concentrations can be analyzed by using Thermal desorption coupled with gas chromatography-mass spectrometry (TDS-GC-MS) with greater sensitivity of masses less than $\sim 50 \mu \mathrm{g}$. This may be applicable for simple matrices like drinking water, where separation is straightforward (Nguyen et al. 2019).

\subsubsection{Differential scanning calorimetry (DSC)}

Differential scanning calorimetry analysis is used to evaluate polymeric MP/NPs by glass transition temperatures ( $\mathrm{Tg}$ ) and depicts chemical structures upon exposure to higher temperatures. Kelkar et al. (2019) applied DSC for physical changes and conversion of virgin plastics to other forms while sterilizing drinking water and wastewater disinfection using different chlorine concentrations. Initial analyses were performed with high-density polyethylene and polypropylene standards, and their respective glass transition temperatures $(\mathrm{Tg})$ were noted. Concerning the traditional values, experimental samples were analyzed, and types of polymers present were identified with heating from ambient temperature to $300{ }^{\circ} \mathrm{C}$ at a heating rate of $5{ }^{\circ} \mathrm{C} / \mathrm{min}$ and cooled to $-80^{\circ} \mathrm{C}$ and enthalpy changes were noted. The DSC analysis upon plastic particles exposure to extreme chlorination conditions resulted in a substantial change, denoted by the difference in melting points and characters of stressed plastics. Likewise, Hebner and Maurer-Jones (2020) calculated DSC exotherms heating and cooling cycles of plastics in moving water. The polymer samples identified have an increased crystallinity, which might be due to the photodegradation of polymers. Plastic polymers melting at low temperatures or glass transition temperature ( $\mathrm{Tg}$ ) show that these plastics having lower molecular weight polymers were attributed to polypropylene and polyethylene samples. 


\section{Interaction energy calculation by DLVO theory and kinetic model}

MP/NPs generation and interactions are necessary to assess its surface chemistry, size and shape in WWTPs processes to predict the existence of plastic nature, which is either single or agglomerate state particles in water (Andrady 2017; Li et al. 2019). Derjaguin, Landau, VerweyOverbeek's (DLVO) theory is used to study the surface energy interactions between suspended solids-polystyrene nanoplastics (PSNPs) and suspended solids-polyethylene MPs (PMPs) particles by applying particle-plate geometry in DLVO calculations (Enfrin et al. 2019). Using theoretical calculations, the interaction energies were treated as particle-particle geometry for PSNPs-PSNPs and plate-plate geometry for PEMPs-PEMPs. Enfrin et al. (2019) explained homogeneous and heterogeneous interactions between the nano/microplastics in water. In homogenous interaction, the surface interaction energies of colloidal MP/NPs have less than $1 \mu \mathrm{m}$ in water as per DLVO theory. From the interparticle distances, the electrostatic repulsion and van der Waals attraction energy between the particles results in agglomeration/aggregation rate in the sample. The potential energy between interparticle distance and kinetic energy due to motion forms a huge effect on dense aggregation/agglomeration and other parameters such as surface area, charge, and ionic strength of sample suspension. In heterogeneous interaction, the aggregation occurs between NPs/ MPs and organic matter or microorganisms. Zhao et al. (2017) studied the marine organic aggregate encapsulate MPs like PP, PS, and PE resulting in the formation of agglomeration. Here, the secretions of microbial extracellular polysaccharides form an interfacial bonding between the plastic particles and the chemicals in the water create the surface interactions between plastics, resulting in agglomeration. As a result, the dispersion pattern can be improved by inserting nucleophile chloro-halides groups to boost negative charge surface density on MP/NPs. Li et al. (2018) looked at how different monovalent and divalent electrolytic solutions affected the aggregation behavior of polystyrene MPs. The aggregation kinetics were achieved by DLVO theory. They have also studied critical coagulation concentration for the aggregation and interaction energies between polystyrene MPs using a combination of theoretical calculations and experimental measurements that could be useful for assessing MP/NPs fate in aquatic environments.

\section{Removal of microplastics in WWTPs}

Wastewater treatment plants (WWTPs) interface natural and mechanical systems. Large quantities of particulate plastic resulting from industrial, domestic, and surface runoff were treated before release into the environment (Frehland et al. 2020; Hu et al. 2019). MPs, unlike suspended solids in standard WWTPs, necessitate the use of settling and filtration equipment to remove MPs (Iyare et al. 2020). Three distinct WWTPs in New York recorded daily particle discharges of 109, 556, 81, 911 particles (Blair et al. 2017). The WWTPs may not completely remove MP/ NPs, but treatment processes involving degradation, generation, and advanced treatment sources should be considered. Nevertheless, MP/NPs concentration downstream is higher than those upstream, suggesting the enormous release of particulate plastic into the natural system is conceivable. The removal of MP/ NPs by the WWTPs can be observed from primary, secondary, and tertiary treatments.

\subsection{Primary treatment}

Primary treatment removes suspended solids and most of the MP/NPs in wastewater. It was evident that preliminary (mechanical) treatment could remove $35-59 \%$ of the microplastics, while primary treatment could remove 23-53\% (Hale et al. 2020). Pretreatment was able to remove bigger microplastics effectively. Rough grille bars $(16-25 \mathrm{~mm})$ and fine grille bars (3-10 mm) used in WWTPs independent MPs of smaller size (Raju et al. 2018; Michielssen et al. 2016). According to Dris et al. (2015), the fraction of massive particles $(1000-5000 \mu \mathrm{m})$ reduced from 45 to $7 \%$ after the preliminary treatment. Surface skimming on primary clarifiers removed light floating MPs, whereas gravity parting removed MPs bound in solid flocs (Simon et al. 2019). Microbeads made of PE were effectively removed by skimming due to their buoyancy and floating on the top of water, grease, and oil particles (Murphy et al. 2016). These findings were consistent with Michielssen et al. (2016) and Sutton et al. (2016), where a considerable decrease of 
microbeads was noticed in the outflow of the WWTPs after primary treatment. In terms of MPs morphologies, pre-treatment may be more effective at removing fibres from wastewater than pieces (Ziajahromi et al. 2017). This is most likely because fibres are abundantly captured in flocs and sedimentation (Talvitie et al. 2015; Magnusson and Norén 2014).

\subsection{Secondary treatment}

Secondary treatment typically includes biological treatment/clarification, which reduces MPs in wastewater by $0.2 \%$ to $14 \%$ (Sun et al. 2019; Besseling et al. 2017). Plastic debris production in the secondary clarifying tank is likely to be aided by sludge flocs or bacterial extracellular polymers in the aeration tank (Carr et al. 2016). Microplastics have an impact on microbial-mediated processes that affect ammonium synthesis (ammoniation) and reduction, as well as inorganic nitrogen biological conversion efficiency (nitrification and denitrification) (Zhang and Chen 2020). Furthermore, the concentrations of microplastics are positively linked with BOD, DO, and total phosphorous. Chemicals (ferric sulfate) and flocculating agents employed during secondary treatment may help to remove MPs by causing suspended particulate matter to combine and form a "floc" (Murphy et al. 2016). Due to protozoa or metazoan feeding, MPs might be trapped in sludge flocs (Scherer et al. 2018; Jeong et al. 2016). Secondly, prolonged interaction of MPs with wastewater aids secondary discharges and removes MP/NPs escaped from skimming/settling practices. These bio-coatings may operate as wetting agents, altering micro/nano plastics surface characteristics and relative densities (Rummel et al. 2017; Fazey and Ryan 2016). Large MPs particles can be removed even more thoroughly during subsequent treatment, resulting in a low abundance. The secondary treatment eliminates additional fragments than fibres due to their abundance and neutral buoyancy (Ziajahromi et al. 2017; Talvitie et al. 2015, 2017).

\subsection{Tertiary treatment}

The tertiary treatment provides further polishing to wastewater and removes microplastics by $0.2-2 \%$ relative to the influent (Sun et al. 2019). In this stage, MP/NPs suspended in the wastewater hinder coagulation, air flotation, microfiltration and affects the disinfection process (chlorine and UV disinfection) (Zhang and Chen 2020). Membrane-related technologies such as disc-filter (DF), rapid sand filtration (RSF), dissolved air flotation (DAF), and membrane bioreactor (MBR) are utilized in the treatment of tertiary effluents (Mintenig et al. 2017). The performance of several membranes in removing MP/NPs found thatMBRshowed relatively higher removal efficacy (99.9\%) trailed by RSF (97\%) and DAF (96\%) (Talvitie et al. 2017). The exclusion of DF varied from 40 to $98.5 \%$. Similar studies were conducted by Schneiderman (2015) in WWTPs and found an absence of microbeads with membrane filters while other advanced filters did. MPs concentrations were considerably lower following ultrafiltration and reverse osmosis (Ziajahromi et al. 2017). In some cases, fibres with fractions $(20-190 \mathrm{~mm})$ were found to be abundant in the final effluent of tertiary treatment (Ziajahromi et al. 2017). This is most likely since fibres can readily pass a filter or membrane longitudinally. MPs were reported to be removed from WWTPs in $98-99.9 \%$ of cases (Simon et al. 2018; Lares et al. 2018; Carr et al. 2016).

\section{Strategies to reduce MP/NPs}

Most interventions to prevent plastic leakage are related to removing MP/NPs from wastewater infrastructure (Pico et al. 2019). One of the effective solutions is to eliminate MP/NPs at the source itself. Improved solid waste infrastructure and management will reduce plastic debris dispersion into environmental matrices. The "GoJelly Project," which employs jellyfish mucus to trap microplastics, is one example of microplastic prevention technology (Schmaltz et al. 2020). The "Cora Ball" and "Fibre Free" are laundry balls used to capture synthetic fibres in the washing machine. At the same time, the "Lint LUV-R" and "Showerloop" are household water systems that filter out microfibers (Schmaltz et al. 2020). Ban on the usage of microbeads alone prevents $>2.9$ trillion pieces of MPs from entering water bodies per year (Prata et al. 2019). Ban or imposing taxes on nonbiodegradable plastics, single-use plastic cutlery, packaging materials, and labeling have been passed recently in various global jurisdictions (Karasik et al. 2020). Bio-based polymers and biodegradable plastics derived from renewable starting materials (starch, 
cellulose, lignin, etc.) are mostly biodegradable (Amulya et al. 2021; Kopperi et al. 2021). Bio-based polyethylene terephthalate (bio-PET), Bio-based polyethylene (bio-PE); Polyethylene furanoate (PEF), Polyhydroxyalkanoates (PHA), Poly(butylene succinate) (PBS), and Polycaprolactone (PCL) accounts for $40 \%$ of the global bioplastics used (Hahladakis et al. 2020; Prata et al. 2019). Swallowing biodegradable MP/NPs also affects health and the environment (Sadeghi et al. 2021).

Mitigation can be achieved through legislation (regulations on the management of plastic waste and products in various industries), technical (bio-innovations including bioplastics), and social awareness (reducing the use of single-use plastics or disposable plastics and adopting recycling habits) (Allouzi et al. 2021). The United States put forth a microbead ban in 2015 (H.R.1321 Microbead-Free Waters Act of 2015), and the European Union launched the singleuse plastics Directive and proposed a ban on intentionally added MPs (EU 2018, Directive (EU) 2019/904) (Catarino et al. 2021). Between 2000 and 2019, near to 28 policies were come into force established on reducing and managing plastic pollution around the globe (Karasik et al. 2020). The Antarctic Treaty, London Convention and Protocol amendments, G20 Action Plan on Marine litter, International Convention for the Prevention of Pollution from Ships (MARPOL) Annex V, and the United Nations Environment Assembly (UNEA) on marine plastic pollution (Karasik et al. 2020). As of 2019, 39 regional policy documents have been adopted in Europe (Schmaltz et al. 2020). In India, the 'Plastic Waste Management Rules, 2016' was implemented to remove all disposable plastic products by 2022 and prohibit the production of plastics below $50 \mu \mathrm{m}$ (Ministry of Environment and Forest, India 2016; Veerasingam et al. 2020). Malaysia has implemented a "No Plastic Bag" campaign by imposing a minimum charge per plastic bag (Allouzi et al. 2021).

\subsection{Circular economy (CE) approach}

Recycling techniques cannot be a comprehensive solution to plastic reduction. Operational issues, infrastructure for collection and sorting, and lack of green methods are inherent limitations of recycling (Bishop et al. 2020). Circular Economy (CE) may be a viable option for reducing the harmful impacts of mass-produced plastics, rising consumption, and the usage of plastic items for short periods (Sandhiya and Ramakrishna, 2020). The end of the product life is one of the most significant contrasts between linear and circular economies. In the linear economics model, the management of a "post-use" product takes the form of dumping, whereas, in the CE model, end-of-life is determined as the product's "first life" (Sadeghi et al. 2021). CE focuses on repair and reconstruction with the aim of continuous use. Managing a finite supply of natural resources and renewing natural systems, closing loops, and waste design are the essential principles of CE (Chae and Hinestroza 2020; Venkata Mohan et al. 2019). Economic considerations are impending for relooping low-value plastic products in the consumption cycle (Fadeeva and Van Berkel 2021). Retailers are crucial in establishing a consumption loop by establishing a viable link between producers and consumers (Fadeeva and Van Berkel 2021). Therefore, manufacturers should create products that cater to consumer preferences while using few virgin resources, reducing toxicity, and increasing recyclability. Adapting technology change in process control, equipment modification, onsite reuse, and recycling helps achieve production loss and curtailing plastic waste at the point source (AliAkbari et al. 2021; Venkata Mohan and Katakojwala, 2021). Mechanical, physical, chemical, biological, and energy recovery are the main recycling technologies employed for recovery (Shamsuyeva and Endres 2021). Recycling can be achieved through the "close-loop" and "openloop" approaches. In closed-loop, plastic's inherent properties stay unchanged, allowing it to be reused as a primary material (bottle-to-bottle recycling), whereas recyclate is used to produce new plastic products (bottle-to-fiber recycling) in an open-loop system (Shamsuyeva and Endres 2021). The recycling technologies are well established for managing single-polymer plastic waste (PET, PE, PP, PS, etc.) and mixed plastic waste (Hahladakis et al. 2020). Recycling rates for PET exceed 10\%, while PS and PP are not yet started (AliAkbari et al. 2021). Recycling plastics will reduce $\mathrm{GHG}$ emissions from $8 \mathrm{GtCO}_{2} \mathrm{e}$ to $4.9 \mathrm{GtCO}_{2} \mathrm{e}$ by 2050 (Zheng and Suh 2019). From an environmental standpoint, the use of microbial polymers and plant-based fibres should be encouraged. The use of biodegradable materials, sustainable management of landfills, designing efficient recycling methods, providing support, incentive laws, and creating 
awareness among stakeholders can help gain traction in adopting CE (Sadeghi et al. 2021). Reprocessing and recycling also create jobs and save energy while downing resource consumption and waste (Chae and Hinestroza 2020).

\section{Conclusion and future perspectives}

Misuse and mismanagement of plastics have led to the accumulation of MP/NPs in the environment, posing a risk to the ecosystem and living beings. They are ubiquitous and released into different environmental compartments (terrestrial, aquatic, and atmospheric depositions) via rivers, lakes, stormwater runoff, sewage, sludge, and wastewater treatment plants. The fate and transport of MP/NPs strongly depend on the physicochemical properties of the plastics in soil and water. MP/NPs accumulation in soil affects the soil productivity, microorganism fecundity and inhibits plant growth. The trophic transfer of MP/NPs to human beings leads to cancer, digestive problems, and cardiovascular diseases. Research priority can be given to MP/NPs transport and accumulation in soil microbiome, crop plants, and trophic transfer of plastic-derived contaminants (additives and chemicals) in the food web. In MP/NPs analysis analytical front, developments in simple and precise tools, validations, and implications in detection, characterization, and quantification still need focus. The traditional use of Raman and FT-IR is already reinforced by the emergence of some promising techniques such as GC-MS performed with pyrolysis or TDS and especially new hyperspectral imaging techniques. Assessing and quantifying MP/NPs in the soil-microbiome-plant system still needs interventions in sample preparation, pre-treatment, and pre-concentration to meet the detection limit of the analytical instruments. In the context of NPs, sampling, pretreatment, and characterization still lack standardization and homogenization of the analyte methods. In addition, it is necessary to establish matching libraries to identify MP/NPs from environmental samples. Particulate plastics from industrial, domestic, and surface runoff are entering wastewater treatment plants (WWTPs) before releasing into the environment. Increasing loads of MP/NPs in sludge digestion system reduces the effectiveness of process and raise operational expenses. Remediation technologies, prioritizing recycling, sustainable waste management, education and awareness, infusing circular models (reduce, reuse, recycle and recover), influxing biobased materials (bioplastics), legislation, policy, and road map are some of the essential prerequisites that may be critically considered for the establishment of sustainable practices in plastic management domain.

Acknowledgements The authors would like to thank CSIRIICT for its support (IICT Manuscript No. IICT/Pubs./2021/ 212).

Author contributions SVM, BRK and HK Conceptualization, SVM, BRK and HK Writing-original draft preparation, SVM Supervision, SVM Funding acquisition. Authors have read and agreed to the published version of the manuscript.

\section{Declarations}

Conflict of interest The authors declare no conflict of interest.

\section{References}

Abbasi S, Keshavarzi B, Moore F, Turner A, Kelly FJ, Dominguez AO, Jaafarzadeh N (2019) Distribution and potential health impacts of microplastics and microrubbers in air and street dusts from Asaluyeh County. Iran Environ Pollut 244:153-164

Alam FC, Sembiring E, Muntalif BS, Suendo V (2019) Microplastic distribution in surface water and sediment river around slum and industrial area (case study: Ciwalengke River, Majalaya district, Indonesia). Chemosphere 224:637-645

AliAkbari R, Mohammad HG, Nariman N, Elaheh K, Seeram R, Mehdi M, Yousef M (2021) High value add bio-based lowcarbon materials: conversion processes and circular economy. J Cleaner Prod, p 126101

Allen S, Allen D, Moss K, Le Roux G, Phoenix VR, Sonke JE (2020) Examination of the ocean as a source for atmospheric microplastics. PloS one, 15(5), p e0232746

Allouzi MMA, Tang DYY, Chew KW, Rinklebe J, Bolan N, Allouzi SMA, Show PL (2021) Micro (nano) plastic pollution: The ecological influence on soil-plant system and human health. Sci Total Environ, p 147815

Amereh F, Babaei M, Eslami A, Fazelipour S, Rafiee M (2020) The emerging risk of exposure to nano (micro) plastics on endocrine disturbance and reproductive toxicity: From a hypothetical scenario to a global public health challenge. Environ Pollut 261:114158

Amulya K, Katakojwala R, Ramakrishna S, Venkata Mohan S (2021) Low carbon biodegradable polymer matrices for sustainable future. Composites Part C: Open Access, p 100111

Andrady AL (2017) The plastic in microplastics: A review. Mar Pollut Bull 119(1):12-22 
Annenkov VV, Danilovtseva EN, Zelinskiy SN, Pal'shin VA (2021) Submicro-and nanoplastics: how much can be expected in water bodies? Environ Pollut 278:116910

Auta HS, Emenike CU, Fauziah SH (2017) Distribution and importance of microplastics in the marine environment: a review of the sources, fate, effects, and potential solutions. Environ Int 102:165-176

Avio CG, Cardelli LR, Gorbi S, Pellegrini D, Regoli F (2017) Microplastics pollution after the removal of the Costa Concordia wreck: first evidences from a biomonitoring case study. Environ Pollut 227:207-214

Azizi SMM, Hai FI, Lu W, Al-Mamun A, Dhar BR (2021) A review of mechanisms underlying the impacts of (nano) microplastics on anaerobic digestion. Bioresour Technol, p 124894

Barboza LGA, Vieira LR, Branco V, Carvalho C, Guilhermino L (2018) Microplastics increase mercury bioconcentration in gills and bioaccumulation in the liver, and cause oxidative stress and damage in Dicentrarchuslabrax juveniles. Sci Rep 8(1):1-9

Bergmann M, Mützel S, Primpke S, Tekman MB, Trachsel J, Gerdts G (2019) White and wonderful? Microplastics prevail in snow from the Alps to the Arctic. Sci Adv 5(8):eaax1157

Besseling E, Quik JT, Sun M, Koelmans AA (2017) Fate of nano-and microplastic in freshwater systems: A modeling study. Environ Pollut 220:540-548

Bianco A, Passananti M (2020) Atmospheric micro and nanoplastics: an enormous microscopic problem. Sustainability 12(18):7327

Birch QT, Potter PM, Pinto PX, Dionysiou DD, Al-Abed SR (2020) Sources, transport, measurement and impact of nano and microplastics in urban watersheds. Rev Environ Sci Biotechnol 19(2):275-336

Bishop G, Styles D, Lens PNL (2020) Recycling of European plastic is a pathway for plastic debris in the ocean. Environ Int 142:105893

Blair RM, Waldron S, Phoenix V, Gauchotte-Lindsay C (2017) Micro-and nanoplastic pollution of freshwater and wastewater treatment systems. Springer Sci Rev 5(1):19-30

Bläsing M, Amelung W (2018) Plastics in soil: analytical methods and possible sources. Sci Total Environ 612:422-435

Boots B, Russell CW, Green DS (2019) Effects of microplastics in soil ecosystems: above and below ground. Environ Sci Technol 53(19):11496-11506

Botterell ZL, Beaumont N, Dorrington T, Steinke M, Thompson RC, Lindeque PK (2019) Bioavailability and effects of microplastics on marine zooplankton: a review. Environ Pollut 245:98-110

Boucher J, Friot D (2017) Primary microplastics in the oceans: a global evaluation of sources (pp 227-229). Gland, Switzerland: Iucn

Brahney J, Mahowald N, Prank M, Cornwell G, Klimont Z, Matsui H, Prather KA (2021) Constraining the atmospheric limb of the plastic cycle. Proc Natl Acad Sci 118(16)

Brand JH, Spencer KL, O'shea FT, Lindsay JE (2018) Potential pollution risks of historic landfills on low-lying coasts and estuaries. Wiley Interdiscip. Rev, 5(1), p e1264
Cabernard L, Roscher L, Lorenz C, Gerdts G, Primpke S (2018) Comparison of Raman and Fourier transform infrared spectroscopy for the quantification of microplastics in the aquatic environment. Environ Sci Technol 52(22):13279-13288

Cai L, Wang J, Peng J, Tan Z, Zhan Z, Tan X, Chen Q (2017) Characteristic of microplastics in the atmospheric fallout from Dongguan city, China: preliminary research and first evidence. Environ Sci Pollut R 24(32):24928-24935

Campanale C, Savino I, Pojar I, Massarelli C, Uricchio VF (2020) A Practical overview of methodologies for sampling and analysis of microplastics in riverine environments. Sustainability 12(17):6755

Carpenter E, Smith K (1972) Plastics on the sargasso sea surface. Science 175:1240-1241. https://doi.org/10.1126/ science.175.4027.1240

Carr SA, Liu J, Tesoro AG (2016) Transport and fate of microplastic particles in wastewater treatment plants. Water Res 91:174-182

Catarino AI, Kramm J, Völker C, Henry TB, Everaert G (2021) Risk posed by microplastics: Scientific evidence and public perception. Curr. Opin. Green Sustain. Chem., p 100467

Ceccarini A, Corti A, Erba F, Modugno F, La Nasa J, Bianchi S, Castelvetro V (2018) The hidden microplastics: new insights and figures from the thorough separation and characterization of microplastics and of their degradation byproducts in coastal sediments. Environ Sci Technol 52(10):5634-5643

Chae Y, An YJ (2017) Effects of micro-and nanoplastics on aquatic ecosystems: Current research trends and perspectives. Mar Pollut Bull 124(2):624-632

Chae Y, Hinestroza J (2020) Building circular economy for smart textiles, smart clothing, and future wearables. Mater Circ Econ 2(1): $1-4$

Chang X, Xue Y, Li J, Zou L, Tang M (2020) Potential health impact of environmental micro and nanoplastics pollution. J Appl Toxicol 40(1):4-15

Chen C, Chen L, Yao Y, Artigas F, Huang Q, Zhang W (2019) Organotin Release from Polyvinyl Chloride Microplastics and Concurrent Photodegradation in Water: Impacts from Salinity, Dissolved Organic Matter, and Light Exposure. Environ Sci Technol 53(18):10741-10752

Chen X, Chen X, Zhao Y, Zhou H, Xiong X, Wu C (2020) Effects of microplastic biofilms on nutrient cycling in simulated freshwater systems. Sci Total Environ, 719, p 137276

Cheung PK, Fok L (2017) Characterisation of plastic microbeads in facial scrubs and their estimated emissions in Mainland China. Water Res 122:53-61

Cincinelli A, Scopetani C, Chelazzi D, Lombardini E, Martellini T, Katsoyiannis A, Fossi MC, Corsolini S (2017) Microplastic in the surface waters of the Ross Sea (Antarctica): occurrence, distribution and characterization by FTIR. Chemosphere 175:391-400

Cole M, Webb H, Lindeque PK, Fileman ES, Halsband C, Galloway TS (2014) Isolation of microplastics in biota-rich seawater samples and marine organisms. Sci Rep 4:4528

Conti GO, Ferrante M, Banni M, Favara C, Nicolosi I, Cristaldi A, Fiore M, Zuccarello P (2020) Micro-and nano-plastics in edible fruit and vegetables. The first diet risks assessment for the general population. Environ Res 187:109677 
Corcoran PL, Biesinger MC, Grifi M (2009) Plastics and beaches: A degrading relationship. Mar Pollut Bull 58:80-84

Courtene-Jones W, Quinn B, Murphy F, Gary SF, Narayanaswamy BE (2017) Optimisation of enzymatic digestion and validation of specimen preservation methods for the analysis of ingested microplastics. Anal Methods 9(9):1437-1445

Cox KD, Covernton GA, Davies HL, Dower JF, Juanes F, Dudas SE (2019) Human consumption of microplastics. Environ Sci Technol 53(12):7068-7074

Cózar A, Echevarría F, González-Gordillo JI, Irigoien X, Úbeda B, Hernández-León S, Palma ÁT, Navarro S, García-deLomas J, Ruiz A, Fernández-de-Puelles ML (2014) Plastic debris in the open ocean. Proc Natl Acad Sci 111(28):10239-10244

De Souza MAA, Lau CW, Kloas W, Bergmann J, Bachelier JB, Faltin E, Becker R, Görlich AS, Rillig MC (2019) Microplastics can change soil properties and affect plant performance. Environ Sci Technol 53(10):6044-6052

Dehaut A, Cassone AL, Frère L, Hermabessiere L, Himber C, Rinnert E, Rivière G, Lambert C, Soudant P, Huvet A, Duflos G (2016) Microplastics in seafood: Benchmark protocol for their extraction and characterization. Environ Poll 215:223-233

Deng Y, Zhang Y, Lemos B, Ren H (2017) Tissue accumulation of microplastics in mice and biomarker responses suggest widespread health risks of exposure. Sci Rep 7:46687

Dobslaw D, Woiski C, Kiel M, Kuch B, Breuer J (2020) Plant uptake, translocation and metabolism of PBDEs in plants of food and feed industry: a review. Rev Environ Sci Biotechnol, pp 1-68

do Sul JAI, Costa MF, Silva-Cavalcanti JS, Araújo MCB (2014) Plastic debris retention and exportation by a mangrove forest patch. Mar Pollut Bull 78(1-2):252-257

Dris R, Gasperi J, Rocher V, Saad M, Renault N, Tassin B (2015) Microplastic contamination in an urban area: a case study in Greater Paris. Environ Chem Lett 12(5):592-599

Duan J, Han J, Zhou H, Lau YL, An W, Wei P, Cheung SG, Yang Y, Tam NFY (2020) Development of a digestion method for determining microplastic pollution in vegetalrich clayey mangrove sediments. Sci Total Environ 707:136030

Dubaish F, Liebezeit G (2013) Suspended microplastics and black carbon particles in the Jade system, Southern North Sea. Water Air Soil Pollut 224(2):1-8

Duemichen E, Braun U, Sturm H, Kraemer R, Deglmann P, Gaan S, Senz R (2015) A new molecular understanding of the thermal degradation of PA 66 doped with metal oxides: experiment and computation. Polym Degrad Stab 120:340-356

Dyachenko A, Mitchell J, Arsem N (2017) Extraction and identification of microplastic particles from secondary wastewater treatment plant (WWTP) effluent. Anal Methods 9(9):1412-1418

Enders K, Lenz R, Stedmon CA, Nielsen TG (2015) Abundance, size and polymer composition of marine microplastics $\geq 10$ $\mu \mathrm{m}$ in the Atlantic Ocean and their modelled vertical distribution. Mar Pollut Bull 100(1):70-81

Enfrin M, Dumée LF, Lee J (2019) Nano/microplastics in water and wastewater treatment processes-Origin, impact and potential solutions. Water Rese 161:621-638
Engwa GA, Ferdinand PU, Nwalo FN, Unachukwu MN (2019) Mechanism and health effects of heavy metal toxicity in humans. Poisoning in the modern world-new tricks for an old dog? Ozgur Karcioglu and Banu Arslan, IntechOpen. https://doi.org/10.5772/intechopen.82511

Evangeliou N, Grythe H, Klimont Z, Heyes C, Eckhardt S, Lopez-Aparicio S, Stohl A (2020) Atmospheric transport is a major pathway of microplastics to remote regions. Nat Commun 11(1):1-11

Fadeeva Z, Van Berkel R (2021) Unlocking circular economy for prevention of marine plastic pollution: an exploration of G20 policy and initiatives. J Environ Manage 277:111457

Fazey FM, Ryan PG (2016) Biofouling on buoyant marine plastics: An experimental study into the effect of size on surface longevity. Environ Poll 210:354-360

Felsing S, Kochleus C, Buchinger S, Brennholt N, Stock F, Reifferscheid G (2018) A new approach in separating microplastics from environmental samples based on their electrostatic behavior. Environ Poll 234:20-28

Feng LJ, Wang JJ, Liu SC, Sun XD, Yuan XZ, Wang SG (2018) Role of extracellular polymeric substances in the acute inhibition of activated sludge by polystyrene nanoparticles. Environ Pollut 238:859-865

Fischer EK, Paglialonga L, Czech E, Tamminga M (2016) Microplastic pollution in lakes and lake shoreline sediments-a case study on Lake Bolsena and Lake Chiusi (central Italy). Environ Poll 213:648-657

Fossi MC, Coppola D, Baini M, Giannetti M, Guerranti C, Marsili L, Panti C, de Sabata E, Clò S (2014) Large filter feeding marine organisms as indicators of microplastic in the pelagic environment: the case studies of the Mediterranean basking shark (Cetorhinus maximus) and fin whale (Balaenopteraphysalus). Mar Environ Res 100:17-24

Frehland S, Kaegi R, Hufenus R, Mitrano DM (2020) Long-term assessment of nanoplastic particle and microplastic fiber flux through a pilot wastewater treatment plant using metal-doped plastics. Water Res 182:115860

Fries E, Dekiff JH, Willmeyer J, Nuelle MT, Ebert M, Remy D (2013) Identification of polymer types and additives in marine microplastic particles using pyrolysis-GC/MS and scanning electron microscopy. Environ Sci: Process Impacts 15(10):1949-1956

Fuller S, Gautam A (2016) A procedure for measuring microplastics using pressurized fluid extraction. Environ Sci Technol 50(11):5774-5780

Gao H, Yan C, Liu Q, Ding W, Chen B, Li Z (2019) Effects of plastic mulching and plastic residue on agricultural production: A meta-analysis. Sci Total Environ 651:484-492

Garcés-Ordóñez O, Castillo-Olaya VA, Granados-Briceño AF, García LMB, Díaz LFE (2019) Marine litter and microplastic pollution on mangrove soils of the Ciénaga Grande de Santa Marta, Colombian Caribbean. Mar Pollut Bull 145:455-462

GESAMP (2016) Sources, fate and effects of microplastics in the marine environment (part2). http://www.gesamp.org/ publications/microplastics-in-the-marineenvironmentpart-2

Geyer R, Jambeck JR, Law KL (2017) Production, use, and fate of all plastics ever made. Sci Adv 3(7):e1700782

Gonçalves JM, Bebianno MJ (2021) Nanoplastics impact on marine biota: a review. Environ Poll, p 116426 
Guo JJ, Huang XP, Xiang L, Wang YZ, Li YW, Li H, Cai QY, Mo $\mathrm{CH}$, Wong MH (2020) Source, migration and toxicology of microplastics in soil. Environ Int 137:105263

Guo X, Wang J (2019) The chemical behaviors of microplastics in marine environment: A review. Mar Pollut Bull 142:1-14

Gutow L, Bartl K, Saborowski R, Beermann J (2019) Gastropod pedal mucus retains microplastics and promotes the uptake of particles by marine periwinkles. Environ Poll 246:688-696

Guzzetti E, Sureda A, Tejada S, Faggio C (2018) Microplastic in marine organism: Environmental and toxicological effects. Environ Toxicol Pharmacol 64:164-171

Hahladakis JN, Lacovidou E, Gerassimidou S (2020) Plastic waste in a circular economy. In: Plastic waste and recycling. Academic Press, pp 481-512

Hale RC, Seeley ME, La Guardia MJ, Mai L, Zeng EY (2020) A global perspective on microplastics. J Geophys Res Oceans 125(1):e2018JC014719

Hartmann NB, Hüffer T, Thompson RC, Hassellöv M, Verschoor A, Daugaard AE, Rist S, Karlsson T, Brennholt N, Cole M, Herrling MP (2019) Are we speaking the same language? Recommendations for a definition and categorization framework for plastic debris

He D, Luo Y, Lu S, Liu M, Song Y, Lei L (2018) Microplastics in soils: analytical methods, pollution characteristics and ecological risks. TrAC Trends Analyt Chem 109:163-172

Hebner TS, Maurer-Jones MA (2020) Characterizing microplastic size and morphology of photodegraded polymers placed in simulated moving water conditions. Environ Sci: Process Impacts 22(2):398-407

Helcoski R, Yonkos LT, Sanchez A, Baldwin AH (2020) Wetland soil microplastics are negatively related to vegetation cover and stem density. Environ Pollut 256:113391

Hermabessiere L, Himber C, Boricaud B, Kazour M, Amara R, Cassone AL, Laurentie M, Paul-Pont I, Soudant P, Dehaut A, Duflos G (2018) Optimization, performance, and application of a pyrolysis-GC/MS method for the identification of microplastics. Anal Bioanal Chem 410(25):6663-6676

Hermsen E, Mintenig SM, Besseling E, Koelmans AA (2018) Quality criteria for the analysis of microplastic in biota samples: a critical review. Environ Sci Technol 52(18):10230-10240

Hidalgo-Ruz V, Gutow L, Thompson RC, Thiel M (2012) Microplastics in the marine environment: a review of the methods used for identification and quantification. Environ Sci Technol 46(6):3060-3075

Hildebrandt L, Mitrano D M, Zimmermann T, Pröfrock D (2020) A nanoplastic sampling and enrichment approach by continuous flow centrifugation. Front Environ Sci

Hirai H, Takada H, Ogata Y, Yamashita R, Mizukawa K, Saha M, Kwan C, Moore C, Gray H, Laursen D, Zettler ER (2011) Organic micropollutants in marine plastics debris from the open ocean and remote and urban beaches. Mar Pollut Bull 62(8):1683-1692

Hodson ME, Duffus-Hodson CA, Clark A, Prendergast-Miller MT, Thorpe KL (2017) Plastic bag derived-microplastics as a vector for metal exposure in terrestrial invertebrates. Environ Sci Technol 51(8):4714-4721
Horton AA, Walton A, Spurgeon DJ, Lahive E, Svendsen C (2017) Microplastics in freshwater and terrestrial environments: evaluating the current understanding to identify the knowledge gaps and future research priorities. Sci Total Environ 586:127-141

Hu Y, Gong M, Wang J, Bassi A (2019) Current research trends on microplastic pollution from wastewater systems: a critical review. Rev Environ Sci Biotechnol 18(2):207-230

Huang JS, Koongolla JB, Li HX, Lin L, Pan YF, Liu S, He WH, Maharana D, Xu XR (2020) Microplastic accumulation in fish from Zhanjiang mangrove wetland, South China. Sci Total Environ 708:134839

Huerta Lwanga E, Gertsen H, Gooren H, Peters P, Salánki T, van der Ploeg M, Besseling E, Koelmans AA, Geissen V (2016) Microplastics in the terrestrial ecosystem: implications for Lumbricusterrestris (Oligochaeta, Lumbricidae). Environ Sci Technol 50(5):2685-2691

Imhof HK, Ivleva NP, Schmid J, Niessner R, Laforsch C (2013) Contamination of beach sediments of a subalpine lake with microplastic particles. Curr Biol 23(19):R867-R868

Iyare PU, Ouki SK, Bond T (2020) Microplastics removal in wastewater treatment plants: a critical review. Environ Sci Water Res 6(10):2664-2675

Jatana S, Callahan LM, Pentland AP, DeLouise LA (2016) Impact of cosmetic lotions on nanoparticle penetration through ex vivo C57BL/6 hairless mouse and human skin: a comparison study. Cosmetics 3(1):6

Jeong J, Choi J (2020) Development of AOP relevant to microplastics based on toxicity mechanisms of chemical additives using ToxCast ${ }^{\mathrm{TM}}$ and deep learning models combined approach. Environ Int 137:105557

Jeong CB, Won EJ, Kang HM, Lee MC, Hwang DS, Hwang UK, Zhou B, Souissi S, Lee SJ, Lee JS (2016) Microplastic sizedependent toxicity, oxidative stress induction, and p-JNK and p-p38 activation in the monogonont rotifer (Brachionuskoreanus). Environ Sci Technol 50(16):8849-8857

Jiang B, Kauffman AE, Li L, McFee W, Cai B, Weinstein J, Lead JR, Chatterjee S, Scott GI, Xiao S (2020) Health impacts of environmental contamination of micro-and nanoplastics: a review. Environ Health Prev Med 25(1):1-15

Karakolis EG, Nguyen B, You JB, Rochman CM, Sinton D (2019) Fluorescent dyes for visualizing microplastic particles and fibers in laboratory-based studies. Environ Sci Technol Lett 6(6):334-340

Karasik R, Vegh T, Diana Z, Bering J, Caldas J, Pickle A, Rittschof D, Virdin J (2020) Years of government responses to the global plastic pollution problem: The plastics policy inventory. NI X 20:20-105

Kelkar VP, Rolsky CB, Pant A, Green MD, Tongay S, Halden RU (2019) Chemical and physical changes of microplastics during sterilization by chlorination. Water Res 163:114871

Kihara S, Köper I, Mata JP, Mc Gillivray DJ (2020) Reviewing nanoplastic toxicology: it's an interface problem. Adv Colloid Interface Sci, p 102337

Kilponen J (2016) Microplastics and harmful substances in urban runoffs and landfill leachates: possible emission sources to marine environment

Koelmans AA, Nor NHM, Hermsen E, Kooi M, Mintenig SM, De France J (2019) Microplastics in freshwaters and 
drinking water: Critical review and assessment of data quality. Water Res 155:410-422

Kokalj AJ, Hartmann NB, Drobne D, Potthoff A, Kühnel D (2021) Quality of nanoplastics and microplastics ecotoxicity studies: refining quality criteria for nanomaterial studies. J Hazard Mater, p 125751

Kopperi H, Amulya K, Venkata Mohan S (2021) Simultaneous biosynthesis of bacterial polyhydroxybutyrate (PHB) and extracellular polymeric substances (EPS): process optimization and Scale-up. Bioresour Technol 341:125735

Kosuth M, Mason SA, Wattenberg EV (2018) Anthropogenic contamination of tap water, beer, and sea salt. PloS one 13(4):e0194970

Koutnik VS, Alkidim S, Leonard J, DePrima F, Cao S, Hoek EM, Mohanty SK (2021) Unaccounted Microplastics in Wastewater Sludge: Where Do They Go? ACS ES\&T Water 1(5):1086-1097

Lahens L, Strady E, Kieu-Le TC, Dris R, Boukerma K, Rinnert E, Gasperi J, Tassin B (2018) Macroplastic and microplastic contamination assessment of a tropical river (Saigon River, Vietnam) transversed by a developing megacity. Environ Pollu 236:661-671

Lamb JB, Willis BL, Fiorenza EA, Couch CS, Howard R, Rader DN, True JD, Kelly LA, Ahmad A, Jompa J, Harvell CD (2018) Plastic waste associated with disease on coral reefs. Science 359(6374):460-462

Lambert S, Scherer C, Wagner M (2017) Ecotoxicity testing of microplastics: Considering the heterogeneity of physicochemical properties. Integr Environ Assess Manag 13(3):470-475

Lares M, Ncibi MC, Sillanpää M, Sillanpää M (2018) Occurrence, identification and removal of microplastic particles and fibers in conventional activated sludge process and advanced MBR technology. Water Res 133:236-246

Lebreton L, Slat B, Ferrari F, Sainte-Rose B, Aitken J, Marthouse R, Hajbane S, Cunsolo S, Schwarz A, Levivier A, Noble K (2018) Evidence that the Great Pacific Garbage Patch is rapidly accumulating plastic. Sci Rep 8(1):1-15

Lechner A, Keckeis H, Lumesberger-Loisl F, Zens B, Krusch R, Tritthart M, Glas M, Schludermann E (2014) The Danube so colourful: a potpourri of plastic litter outnumbers fish larvae in Europe's second largest river. Environ Poll 188:177-181

Lee KW, Shim WJ, Kwon OY, Kang JH (2013) Size-dependent effects of micro polystyrene particles in the marine copepod Tigriopusjaponicus. Environ Sci Technol 47(19):11278-11283

Lehtiniemi M, Hartikainen S, Näkki P, Engström-Öst J, Koistinen A, Setälä O (2018) Size matters more than shape: ingestion of primary and secondary microplastics by small predators. Food Webs 17:e00097

Lei L, Liu M, Song Y, Lu S, Hu J, Cao C, Xie B, Shi H, He D (2018) Polystyrene (nano) microplastics cause size-dependent neurotoxicity, oxidative damage and other adverse effects in Caenorhabditiselegans. Environ Sci Nano 5(8):2009-2020

Li J, Yang D, Li L, Jabeen K, Shi H (2015) Microplastics in commercial bivalves from China. Environ Pollu 207:190-195

Li J, Zhang K, Zhang H (2018a) Adsorption of antibiotics on microplastics. Environ Pollut 237:460-467
Li S, Liu H, Gao R, Abdurahman A, Dai J, Zeng F (2018b) Aggregation kinetics of microplastics in aquatic environment: complex roles of electrolytes, $\mathrm{pH}$, and natural organic matter. Environ Pollu 237:126-132

Li QC, Lai YJ, Yu SJ, Li P, Zhou XX, Dong LJ, Liu X, Yao ZW, Liu JF (2021) Sequential Isolation of Microplastics and Nanoplastics in Environmental Waters by Membrane Filtration. Followed by Cloud-Point Extraction Analytical Chemistry 93(10):4559-4566

Li L, Geng S, Li Z, Song K (2020) Effect of microplastic on anaerobic digestion of wasted activated sludge. Chemosphere 247:125874

Li R, Yu L, Chai M, Wu H, Zhu X (2020) The distribution, characteristics and ecological risks of microplastics in the mangroves of Southern China. Sci Total Enviro 708:135025

Li Y, Wang X, Fu W, Xia X, Liu C, Min J, Zhang W, Crittenden JC (2019) Interactions between nano/micro plastics and suspended sediment in water: Implications on aggregation and settling. Water Res 161:486-495

Liu H, Yang X, Liu G, Liang C, Xue S, Chen H, Ritsema CJ, Geissen V (2017) Response of soil dissolved organic matter to microplastic addition in Chinese loess soil. Chemosphere 185:907-917

Liu M, Lu S, Song Y, Lei L, Hu J, Lv W, Zhou W, Cao C, Shi H, Yang X, He D (2018) Microplastic and mesoplastic pollution in farmland soils in suburbs of Shanghai, China. Environ Pollut 242:855-862

Liu P, Qian L, Wang H, Zhan X, Lu K, Gu C, Gao S (2019a) New insights into the aging behavior of microplastics accelerated by advanced oxidation processes. Environ Sci Technol 53(7):3579-3588

Liu S, Jian M, Zhou L, Li W (2019b) Distribution and characteristics of microplastics in the sediments of Poyang Lake. China Water Sci Technol 79(10):1868-1877

Liu Q, Li L, Zhao X, Song K (2021) An evaluation of the effects of nanoplastics on the removal of activated-sludge nutrients and production of short chain fatty acid. Process Saf Environ Prot 148:1070-1076

Löder MG, Imhof HK, Ladehoff M, Löschel LA, Lorenz C, Mintenig S, Piehl S, Primpke S, Schrank I, Laforsch C, Gerdts G (2017) Enzymatic purification of microplastics in environmental samples. Environ Sci Technol 51(24):14283-14292

Long Z, Pan Z, Wang W, Ren J, Yu X, Lin L, Lin H, Chen H, Jin $X$ (2019) Microplastic abundance, characteristics, and removal in wastewater treatment plants in a coastal city of China. Water Res 155:255-265

Lucas N, Bienaime C, Belloy C, Queneudec M, Silvestre F, Nava-Saucedo JE (2008) Polymer biodegradation: Mechanisms and estimation techniques-A review. Chemosphere 73:429-442

Lv W, Zhou W, Lu S, Huang W, Yuan Q, Tian M, Lv W, He D (2019) Microplastic pollution in rice-fish co-culture system: A report of three farmland stations in Shanghai, China. Sci Total Environ 652:1209-1218

Magnusson K, Norén F (2014) Screening of microplastic particles in and down-stream a wastewater treatment plant. IVL Swedish Environmental Research Institute. DOCUMENT NV-05269-13 
Mahon AM, O'Connell B, Healy MG, O'Connor I, Officer R, Nash R, Morrison L (2017) Microplastics in sewage sludge: effects of treatment. Environ Sci Technol 51(2):810-818

Mariano S, Tacconi S, Fidaleo M, Rossi M, Dini L (2021) Micro and nanoplastics identification: classic methods and innovative detection techniques. Front Toxicol 3:2

Markic A, Gaertner JC, Gaertner-Mazouni N, Koelmans AA (2020) Plastic ingestion by marine fish in the wild. Crit Rev Environ Sci Technol 50(7):657-697

Mason SA, Welch VG, Neratko J (2018) Synthetic polymer contamination in bottled water. Front Chem 6:407

Masura J, Baker J, Foster G, Arthur C (2015) Laboratory methods for the analysis of microplastics in the marine environment: recommendations for quantifying synthetic particles in waters and sediments. Siver Spring, MD, NOAA Marine Debris Division, 31 pp. (NOAA Technical Memorandum NOS-OR\&R-48). https://doi.org/10.25607/ OBP-604

Mateos-Cárdenas A, Scott DT, Seitmaganbetova G, van Pelt FNAM, A K J M, (2019) Polyethylene microplastics adhere to Lemna minor (L.), yet have no effects on plant growth or feeding by Gammarusduebeni (Lillj.). Sci Total Environ 689:413-421

Mateos-Cárdenas A, van Pelt FN, O’Halloran J, Jansen MA (2021) Adsorption, uptake and toxicity of micro-and nanoplastics: Effects on terrestrial plants and aquatic macrophytes. Environ Pollut, p 117183

McGivney E, Cederholm L, Barth A, Hakkarainen M, Hamacher-Barth E, Ogonowski M, Gorokhova E (2020) Rapid Physicochemical Changes in Microplastic Induced by Biofilm Formation. Front Bioeng Biotechno 8:205

Meng Y, Kelly FJ, Wright SL (2020) Advances and challenges of microplastic pollution in freshwater ecosystems: a UK perspective. Environ Pollut, p 113445

Michielssen MR, Michielssen ER, Ni J, Duhaime MB (2016) Fate of microplastics and other small anthropogenic litter (SAL) in wastewater treatment plants depends on unit processes employed. Environ Sci Water Res 2(6):1064-1073

Mintenig SM, Int-Veen I, Löder MG, Primpke S, Gerdts G (2017) Identification of microplastic in effluents of waste water treatment plants using focal plane array-based microFourier-transform infrared imaging. Water Res 108:365-372

Mofijur M, Ahmed SF, Rahman SA, Siddiki SYA, Islam AS, Shahabuddin M, Ong HC, Mahlia TI, Djavanroodi F, Show PL (2021) Source, distribution and emerging threat of micro-and nanoplastics to marine organism and human health: Socio-economic impact and management strategies. Environ Res 195:110857

Munno K, Helm PA, Jackson DA, Rochman C, Sims A (2018) Impacts of temperature and selected chemical digestion methods on microplastic particles. Environ Toxicol Chem 37(1):91-98

Murphy F, Ewins C, Carbonnier F, Quinn B (2016) Wastewater treatment works (WwTW) as a source of microplastics in the aquatic environment. Environ Sci Technol 50(11):5800-5808
Murray A, Örmeci B (2020) Removal effectiveness of nanoplastics $(<400 \mathrm{~nm})$ with separation processes used for water and wastewater treatment. Water 12(3):635

Murray CC, Maximenko N, Lippiatt S (2018) The influx of marine debris from the Great Japan Tsunami of 2011 to North American shorelines. Mar Pollut Bull 132:26-32

Naidoo T, Thompson RC, Rajkaran A (2020) Quantification and characterisation of microplastics ingested by selected juvenile fish species associated with mangroves in KwaZulu-Natal, South Africa. Environ Pollut 257:113635

Naik RK, Naik MM, D'Costa PM, Shaikh F (2019) Microplastics in ballast water as an emerging source and vector for harmful chemicals, antibiotics, metals, bacterial pathogens and HAB species: a potential risk to the marine environment and human health. Mar Pollut Bull 149:110525

Ng EL, Lwanga EH, Eldridge SM, Johnston P, Hu HW, Geissen V, Chen D (2018) An overview of microplastic and nanoplastic pollution in agroecosystems. Sci Total Environ 627:1377-1388

Nguyen B, Claveau-Mallet D, Hernandez LM, Xu EG, Farner JM, Tufenkji N (2019) Separation and analysis of microplastics and nanoplastics in complex environmental samples. Acc Chem Res 52(4):858-866

Nizzetto L, Futter M, Langaas S (2016) Are agricultural soils dumps for microplastics of urban origin? Environ Sci Technol 50(20):10777-10779

Nor NHM, Obbard JP (2014) Microplastics in Singapore's coastal mangrove ecosystems. Mar Pollut Bull 79(1-2):278-283

O’Neill SM, Lawler J (2021) Knowledge gaps on Micro and Nanoplastics and human health: a critical review. Case Studies in Chemical and Environmental Engineering, p 100091

Oberbeckmann S, Kreikemeyer B, Labrenz M (2018) Environmental factors support the formation of specific bacterial assemblages on microplastics. Front Biol 8:2709

O'Connor D, Pan S, Shen Z, Song Y, Jin Y, Wu WM, Hou D (2019) Microplastics undergo accelerated vertical migration in sand soil due to small size and wet-dry cycles. Environ Pollut 249:527-534

O’Donovan S, Mestre NC, Abel S, Fonseca TG, Carteny CC, Willems T, Prinsen E, Cormier B, Keiter SS, Bebianno MJ (2020) Effects of the UV filter, oxybenzone, adsorbed to microplastics in the clam Scrobiculariaplana. Sci Total Environ 733:139102

Omidi A, Naeemipoor H, Hosseini M (2012) Plastic debris in the digestive tract of sheep and goats: an increasing environmental contamination in Birjand, Iran. Bull Environ Contam Toxicol 88(5):691-694

OSPAR Commission (2014) Marine litter regional action plan. OSPAR Secretariat, London

Patricio Silva AL, Prata JC, Duarte AC, Barcelò D, RochaSantos T (2021) An urgent call to think globally and act locally on landfill disposable plastics under and after covid19 pandemic: Pollution prevention and technological (Bio) remediation solutions. Chem Eng J, p 131201

Peng J, Wang J, Cai L (2017) Current understanding of microplastics in the environment: occurrence, fate, risks, and what we should do. Integr Environ Assess Manag 13(3):476-482 
Pico Y, Alfarhan A, Barcelo D (2019) Nano-and microplastic analysis: Focus on their occurrence in freshwater ecosystems and remediation technologies. TrAC Trends Anal Chem 113:409-425

Pitt JA, Kozal JS, Jayasundara N, Massarsky A, Trevisan R, Geitner N, Wiesner M, Levin ED, Di Giulio RT (2018) Uptake, tissue distribution, and toxicity of polystyrene nanoparticles in developing zebrafish (Danio rerio). Aquat Toxicol 194:185-194

Plastics Europe (2017) Plastics - the Facts 2017: an analysis of European Plastic Production, Demand and Waste Data. https://www.plasticseurope.org/application/files/1715/ 2111/1527/Plastics_the_facts_2017_FINAL_for_website. pdf

Prata JC (2018) Airborne microplastics: consequences to human health? Environ Pollut 234:115-126

Prata JC, Silva ALP, Da Costa JP, Mouneyrac C, Walker TR, Duarte AC, Rocha-Santos T (2019) Solutions and integrated strategies for the control and mitigation of plastic and microplastic pollution. Int J Environ Res Public Health 16(13): 2411

Raju S, Carbery M, Kuttykattil A, Senathirajah K, Subash chandra bose S R, Evans G, Thavamani P, (2018) Transport and fate of microplastics in wastewater treatment plants: implications to environmental health. Rev Environ Sci Biotechnol 17(4):637-653

Ramos JA, Barletta M, Costa MF (2012) Ingestion of nylon threads by Gerreidae while using a tropical estuary as foraging grounds. Aquat Biol 17(1):29-34

Ramos L, Berenstein G, Hughes EA, Zalts A, Montserrat JM (2015) Polyethylene film incorporation into the horticultural soil of small periurban production units in Argentina. Sci Total Environ 523:74-81

Revel M, Châtel A, Mouneyrac C (2018) Micro (nano) plastics: A threat to human health? Curr Opin Environ Sci Health $1: 17-23$

Rezaei M, Riksen MJ, Sirjani E, Sameni A, Geissen V (2019) Wind erosion as a driver for transport of light density microplastics. Sci Total Envirot 669:273-281

Riascos JM, Valencia N, Peña EJ, Cantera JR (2019) Inhabiting the technosphere: The encroachment of anthropogenic marine litter in Neotropical mangrove forests and its use as habitat by macrobenthic biota. Mar Pollut Bull 142:559-568

Rist S, Baun A, Almeda R, Hartmann NB (2019) Ingestion and effects of micro-and nanoplastics in blue mussel (Mytilus edulis) larvae. Mar Pollut Bull 140:423-430

Rochman CM, Brookson C, Bikker J, Djuric N, Earn A, Bucci K, Athey S, Huntington A, McIlwraith H, Munno K, De Frond H (2019) Rethinking microplastics as a diverse contaminant suite. Environ Toxicol Chem 38(4):703-711

Rummel CD, Jahnke A, Gorokhova E, Kühnel D, SchmittJansen M (2017) Impacts of biofilm formation on the fate and potential effects of microplastic in the aquatic environment. Environ Sci Technol Lett 4(7):258-267

Sadeghi P, Sadeghi B, Marfavi Y, Kowsari E, Ramakrishna S, Chinnappan A (2021) Addressing the Challenge of Microfiber Plastics as the Marine Pollution Crisis Using Circular Economy Methods: a Review. Mater Circ Econ 3(1):1-23
Sanchez W, Bender C, Porcher JM (2014) Wild gudgeons (Gobiogobio) from French rivers are contaminated by microplastics: preliminary study and first evidence. Environ Res 128:98-100

Sandhiya R, Ramakrishna S (2020) Investigating the applicability of blockchain technology and ontology in plastics recycling by the adoption of ZERO plastic model. Mater Circ Econ 2:13

Santillo D, Miller K, Johnston P (2017) Microplastics as contaminants in commercially important seafood species. Integr Environ Assess Manage 13:516-521

Scherer C, Weber A, Lambert S, Wagner M (2018) Interactions of microplastics with freshwater biota. In: Freshwater microplastics (pp 153-180). Springer, Cham

Schmaltz E, Melvin EC, Diana Z, Gunady EF, Rittschof D, Somarelli JA, Virdin J, Dunphy-Daly MM (2020) Plastic pollution solutions: emerging technologies to prevent and collect marine plastic pollution. Environ Int 144:106067

Schneiderman ET (2015) Discharging microbeads to our waters: an examination of wastewater treatment plants in New York

Schwaferts C, Niessner R, Elsner M, Ivleva NP (2019) Methods for the analysis of submicrometer-and nanoplastic particles in the environment. TrAC Trend Anal Chem 112:52-65

Schwinghammer L, Krause S, Schaum C (2020) Determination of large microplastics: wet-sieving of dewatered digested sludge, co-substrates, and compost. Water Sci Technol

Schymanski D, Goldbeck C, Humpf HU, Fürst P (2018) Analysis of microplastics in water by micro-Raman spectroscopy: release of plastic particles from different packaging into mineral water. Water Res 129:154-162

Senathirajah K, Attwood S, Bhagwat G, Carbery M, Wilson S, Palanisami $T$ (2021) Estimation of the mass of microplastics ingested-A pivotal first step towards human health risk assessment. J Hazard Mater 404:124004

Seth CK, Shriwastav A (2018) Contamination of Indian sea salts with microplastics and a potential prevention strategy. Environ Sci Pollut Res 25(30):30122-30131

Shamsuyeva M, Endres HJ (2021) Plastics in the context of the circular economy and sustainable plastics recycling: comprehensive review on research development, standardisation and market. Composites Part C: Open Access, p 100168

Shen M, Zhang Y, Zhu Y, Song B, Zeng G, Hu D, Wen X, Ren X (2019) Recent advances in toxicological research of nanoplastics in the environment: A review. Environ Pollut 252:511-521

Shim WJ, Song YK, Hong SH, Jang M (2016) Identification and quantification of microplastics using Nile Red staining. Mar Pollut Bull 113(1-2):469-476

Simon M, van Alst N, Vollertsen J (2018) Quantification of microplastic mass and removal rates at wastewater treatment plants applying Focal Plane Array (FPA)-based Fourier Transform Infrared (FT-IR) imaging. Water Res 142:1-9

Simon M, Vianello A, Vollertsen J (2019) Removal of $>10 \mu \mathrm{m}$ Microplastic Particles from Treated Wastewater by a Disc Filter. Water 11(9):1935

Song YK, Hong SH, Eo S, Jang M, Han GM, Isobe A, Shim WJ (2018) Horizontal and vertical distribution of microplastics 
in Korean coastal waters. Environ Sci Technol 52(21):12188-12197

Stock F, Kochleus C, Bänsch-Baltruschat B, Brennholt N, Reifferscheid G (2019) Sampling techniques and preparation methods for microplastic analyses in the aquatic environment-A review. TrAC Trends Analyt Chem

Stockholm convention, UNEP, Marine Pollution Litter and Microplastics, Stockholm convention on Persistent Organic Pollutants (2018)

Sun J, Dai X, Wang Q, van Loosdrecht MC, Ni BJ (2019) Microplastics in wastewater treatment plants: Detection, occurrence and removal. Water Res 152:21-37

Sun H, Lei C, Xu J, Li R (2021) Foliar uptake and leaf-to-root translocation of nanoplastics with different coating charge in maize plants. J Hazard Mater 416:125854

Sun J, Zhu ZR, Li WH, Yan X, Wang LK, Zhang L, Jin J, Dai X, Ni B J (2021) Revisiting Microplastics in Landfill Leachate: Unnoticed Tiny Microplastics and Their Fate in Treatment Works. Water Res 190:116784

Sutton R, Mason SA, Stanek SK, Willis-Norton E, Wren IF, Box C (2016) Microplastic contamination in the San Francisco Bay, California, USA. Mar Pollut Bull 109(1):230-235

Tagg AS, Harrison JP, Ju-Nam Y, Sapp M, Bradley EL, Sinclair CJ, Ojeda JJ (2017) Fenton's reagent for the rapid and efficient isolation of microplastics from wastewater. Chem Comm 53(2):372-375

Talvitie J, Heinonen M, Pääkkönen JP, Vahtera E, Mikola A, Setälä O, Vahala R (2015) Do wastewater treatment plants act as a potential point source of microplastics? Preliminary study in the coastal Gulf of Finland. Baltic Sea Water Sci Technol 72(9):1495-1504

Talvitie J, Mikola A, Koistinen A, Setälä O (2017) Solutions to microplastic pollution-Removal of microplastics from wastewater effluent with advanced wastewater treatment technologies. Water Res 123:401-407

Tchounwou PB, Yedjou CG, Patlolla AK, Sutton DJ (2012) Heavy metal toxicity and the environment. Molecular, clinical and environmental toxicology, pp 133-164

Thompson RC (2015) Microplastics in the marine environment: sources, consequences and solutions. In: Marine anthropogenic litter (pp 185-200). Springer, Cham

UNEP (2014) Plastic debris in the ocean. UNEP Year Book 2014 Emerging issues update

Uurasjärvi E, Hartikainen S, Setälä O, Lehtiniemi M, Koistinen A (2020) Microplastic concentrations, size distribution, and polymer types in the surface waters of a northern European lake. Water Environ Res 92(1):149-156

Van Cauwenberghe L, Janssen CR (2014) Microplastics in bivalves cultured for human consumption. Environ Pollut 193:65-70

Van den Berg P, Huerta-Lwanga E, Corradini F, Geissen V (2020) Sewage sludge application as a vehicle for microplastics in eastern Spanish agricultural soils. Environ Pollut 261:114198

Veerasingam S, Ranjani M, Venkatachalapathy R, Bagaev A, Mukhanov V, Litvinyuk D, Verzhevskaia L, Guganathan L, Vethamony P (2020) Microplastics in different environmental compartments in India: Analytical methods, distribution, associated contaminants and research needs. TrAC Trends Anal Chem 133:116071
Venkata Mohan S and Katakojwala R (2021) The Circular Chemistry Conceptual Framework: a way forward to Sustainability in Industry 4.0. Curr Opin Green Sustain Chem 28:100434

Venkata Mohan S, Dahiya S, Amulya K, Ranaprathap K, Vanitha TK (2019) Can circular bioeconomy be fueled by waste biorefineries - a closer look. Bioresour Technol Rep 7:100277

Verla AW, Enyoh CE, Verla EN, Nwarnorh KO (2019) Microplastic-toxic chemical interaction: a review study on quantified levels, mechanism and implication. SN Appl Sci 1(11): $1-30$

Viršek M K, Lovšin M N, Koren Š, Kržan A, Peterlin M (2017) Microplastics as a vector for the transport of the bacterial fish pathogen species Aeromonas salmonicida. Mar Pollut Bull 125(1-2):301-309

Wahl A, Le Juge C, Davranche M, El Hadri H, Grassl B, Reynaud S, Gigault J (2021) Nanoplastic occurrence in a soil amended with plastic debris. Chemosphere 262:127784

Walker TR (2021) (Micro) plastics and the UN sustainable development goals. Curr Opin Green Sustain Chem 100497

Wang J, Lv S, Zhang M, Chen G, Zhu T, Zhang S, Teng Y, Christie P, Luo Y (2016) Effects of plastic film residues on occurrence of phthalates and microbial activity in soils. Chemosphere 151:171-177

Wang W, Ndungu AW, Li Z, Wang J (2017) Microplastics pollution in inland freshwaters of China: a case study in urban surface waters of Wuhan, China. Sci Total Environ 575:1369-1374

Wang W, Ge J, Yu X (2020a) Bioavailability and toxicity of microplastics to fish species: a review. Ecotoxicol Environ Saf 189:109913

Wang W, Ge J, Yu X, Li H (2020b) Environmental fate and impacts of microplastics in soil ecosystems: progress and perspective. Sci Total Environ 708:134841

Wang Q, Adams CA, Wang F, Sun Y, Zhang S (2021) Interactions between microplastics and soil fauna: a critical review. Crit Rev Environ Sci Technol, pp 1-33

Wei W, Huang QS, Sun J, Wang JY, Wu SL, Ni BJ (2019) Polyvinyl chloride microplastics affect methane production from the anaerobic digestion of waste activated sludge through leaching toxic bisphenol-A. Environ Sci Technol 53(5):2509-2517

Weinstein JE, Crocker BK, Gray AD (2016) From macroplastic to microplastic: Degradation of high-density polyethylene, polypropylene, and polystyrene in a salt marsh habitat. Environ Toxicol Chem 35(7):1632-1640

Wong KHJ, Lee KK, Kuok Ho DT, Yap PS (2020) Microplastics in freshwater and terrestrial environments: prevalence, facts, impats and sustainable solutions. Sci Total Environ. https://doi.org/10.1016/j.scitotenv.2020.137512

Wright SL, Ulke J, Font A, Chan KL A, Kelly FJ (2020) Atmospheric microplastic deposition in an urban environment and an evaluation of transport. Environ Int 136:105411

Wu WM, Yang J, Criddle CS (2017) Microplastics pollution and reduction strategies. Front Environ Sci Eng 11(1):6

Wu P, Huang J, Zheng Y, Yang Y, Zhang Y, He F, Chen H, Quan G, Yan J, Li T, Gao B (2019) Environmental 
occurrences, fate, and impacts of microplastics. Ecotoxicol Environ Saf 184:109612

Xu M, Halimu G, Zhang Q, Song Y, Fu X, Li Y, Li Y, Zhang H (2019) Internalization and toxicity: A preliminary study of effects of nanoplastic particles on human lung epithelial cell. Sci Total Environ 694:133794

Xu S, Ma J, Ji R, Pan K, Miao A J (2019) Microplastics in aquatic environments: occurrence, accumulation, and biological effects. Sci Total Environ, p 134699

Xu C, Zhang B, Gu C, Shen C, Yin S, Aamir M, Li F (2020) Are we underestimating the sources of microplastic pollution in terrestrial environment? J Hazard Mater 400:123228

Yang X, Lwanga EH, Bemani A, Gertsen H, Salanki T, Guo X, Fu H, Xue S, Ritsema C, Geissen V (2019a) Biogenic transport of glyphosate in the presence of LDPE microplastics: A mesocosm experiment. Environ Poll 245:829-835

Yang L, Li K, Cui S, Kang Y, An L, Lei K (2019b) Removal of microplastics in municipal sewage from China's largest water reclamation plant. Water Res 155:175-181

Yee MSL, Hii LW, Looi CK, Lim WM, Wong SF, Kok YY, Tan BK, Wong CY, Leong CO (2021) Impact of microplastics and nanoplastics on human health. Nanomaterials 11(2):496

Yuan W, Zhou Y, Liu X, Wang J (2019) New perspective on the nanoplastics disrupting the reproduction of an endangered fern in artificial freshwater. Environ Sci Technol 53(21):12715-12724

Zada L, Leslie HA, Vethaak AD, Tinnevelt GH, Jansen JJ, de Boer JF, Ariese F (2018) Fast microplastics identification with stimulated Raman scattering microscopy. J Raman Spectrosc 49(7):1136-1144

Zhang GS, Liu YF (2018) The distribution of microplastics in soil aggregate fractions in south-western China. Sci Tot Environ 642:12-20

Zhang D, Liu HB, Hu WL, Qjn XH, Yan CR, Wang HY (2016) The status and distribution characteristics of residual mulching film in Xinjiang. China $J$ Integr Agric 15(11):2639-2646

Zhang Q, Xu EG, Li J, Chen Q, Ma L, Zeng EY, Shi H (2020) A review of microplastics in table salt, drinking water, and air: direct human exposure. Environ Sci Technol 54(7):3740-3751

Zhang Z, Chen Y (2020). Effects of microplastics on wastewater and sewage sludge treatment and their removal: a review. Chem Eng Sci 382:122955

Zhao S, Danley M, Ward JE, Li D, Mincer TJ (2017) An approach for extraction, characterization and quantitation of microplastic in natural marine snow using Raman microscopy. Anal Methods 9(9):1470-1478

Zheng J, Suh S (2019) Strategies to reduce the global carbon footprint of plastics. Nat Clim Chang 9(5):374-378

Zhou G, Wang Q, Zhang J, Li Q, Wang Y, Wang M, Huang X (2020) Distribution and characteristics of microplastics in urban waters of seven cities in the Tuojiang River basin, China. Environ Res 189:109893

Zhu H, Fu SF, Su Y, Zhang Y (2021) Effects of nanoplastics on microalgae and their trophic transfer along food chain: Recent advances and perspectives. Environ Sci Processes Impacts. https://doi.org/10.1039/D1EM00438G

Ziajahromi S, Neale PA, Rintoul L, Leusch FD (2017) Wastewater treatment plants as a pathway for microplastics: development of a new approach to sample wastewaterbased microplastics. Water Res 112:93-99

Zuccarello P, Ferrante M, Cristaldi A, Copat C, Grasso A, Sangregorio D, Fiore M, Conti G O (2019) Exposure to microplastics $(<10 \mu \mathrm{m})$ associated to plastic bottles

Publisher's Note Springer Nature remains neutral with regard to jurisdictional claims in published maps and institutional affiliations. 